\title{
Why do large-scale agricultural investments induce different socio-economic, food security, and environmental impacts? Evidence from Kenya, Madagascar, and Mozambique
}

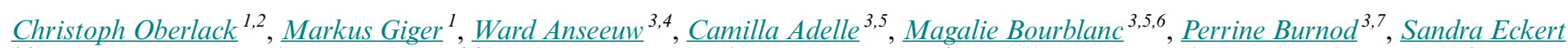 \\ ${ }_{1,2}$. We gavehu Fitawek $^{6}$, Eve Fouilleux $^{3,8}{ }^{3}$ Sheryl L. Hendriks $^{6}$, Boniface Kiteme $^{9}$, Livhuwani Masola $^{6}$, Zaka Diana Mawoko ${ }^{6}$, Sara \\ $\underline{\text { Mercandalli }}^{3}, \underline{\text { Aurélien Reys }}^{3}$, Mava da Silva $^{10}$, Michael van der Laan $^{10}$, Julie G. Zaehringer $^{1,2}$ and $^{\text {Peter Messerli }}{ }^{2,11}$
}

\begin{abstract}
Large-scale agricultural investments (LAIs) transform land use systems worldwide. There is, however, limited understanding about how the common global drivers of land use change induce different forms of agricultural investment and produce different impacts on the ground. This article provides a cross-country comparative analysis of how differences in business models, land use changes, and governance systems explain differences in socio-economic, food security, and environmental impacts of LAIs in Kenya, Madagascar, and Mozambique. It brings together results on these aspects generated in the AFGROLAND project that collected data in a multi-method approach via household surveys, business model surveys, semi-structured household interviews, life-cycle assessments of farm production, analysis of remote-sensing data, key informant interviews, and document analysis. For the present project synthesis, we combined a collaborative expert workshop with a comparative analysis of 16 LAIs. The results show that the LAIs follow four distinctive impact patterns, ranging from widespread adverse impacts to moderate impacts. Results demonstrate how the following conditions influence how the global drivers of land use change translate into different LAIs and different impacts on the ground: labor intensity, prior land use, utilization of land, farm size, type of production, experience in local agriculture, land tenure security, accountability of state and local elites, the mobilization capacity of civil society, expansion of resource frontiers, agricultural intensification, and indirect land use change. The results indicate that commercial agriculture can be a component in sustainable development strategies under certain conditions, but that these strategies will fail without substantial, sustained increases in the economic viability and inclusiveness of smallholder agriculture, land tenure security, agro-ecological land management, and support for broader patterns of endogenous agrarian transformation.
\end{abstract}

Key Words: agricultural investments; business models; environment; food security; governance; land use change; livelihoods

\section{INTRODUCTION}

Large-scale investments in agriculture (LAIs) are transforming land use and food systems in their targeted regions worldwide. The long-term global drivers of these social-ecological transformations persist: global population growth, changing diets and recurrent national food shortages (Zoomers 2010, Nolte et al. 2016), energy system transitions (Scheidel and Sorman 2012, Antonelli et al. 2015), climate change responses (Davis et al. 2015), private capital in search of investment opportunities (Ceddia 2019), national development strategies (Cotula 2012), and geopolitics (Oliveira 2016). They have given rise to a rush of largescale agricultural investments (LAIs) across Africa, Asia, Latin America, and Eastern Europe over the last decade (Anseeuw et al. 2012, Nolte et al. 2016), leading to major concerns for global sustainable development (Deininger and Byerlee 2012, Dell'Angelo et al. 2017a).

Large-scale agricultural investments affect livelihoods, food security, and the environment in their target regions in diverse ways (German et al. 2011, Oberlack et al. 2016). Some studies found positive effects on employment and rural welfare (Petrick et al. 2013). Other studies showed that LAIs displace land users, undermine resilience, disrupt customary land tenure institutions, and lead to livelihood destruction, deforestation, environmental degradation, and increased conflict (e.g., Ahrends et al. 2015, Bottazzi et al. 2016, Haller et al. 2019). Therefore, the socioeconomic, food security, and environmental impacts of LAIs differ markedly from one setting to another (Hall et al. 2015a).

However, there is limited understanding about how the common global drivers of land use change generate different forms of agricultural investment and different impacts on the ground. Such understanding would be important to identify entry points and levers for policy action at national and international scales. These limitations are partly due to dominant methodologies that investigate LAIs either by means of isolated case studies or national/global inventories (Oya 2013). More cross-country comparative analyses of LAIs are needed to close this knowledge gap (Cotula et al. 2014, Schoneveld 2014, Hall et al. 2015a, Breu et al. 2016, Dell'Angelo et al. 2017b, Haller et al. 2019).

This study provides a cross-country comparative analysis of the social-ecological dynamics associated with LAIs. Specifically, this study analyzes how differences in business models, land use

${ }^{1}$ Centre for Development and Environment (CDE), University of Bern, Switzerland, ${ }^{2}$ Institute of Geography, University of Bern, Switzerland, ${ }^{3}$ French Agricultural Research Centre for International Development (CIRAD), France, ${ }^{4}$ International Land Coalition (ILC), Rome, Italy, ${ }^{5}$ Centre for the Study of Governance Innovation, University of Pretoria, South Africa, ${ }^{6}$ Department of Agricultural Economics, Extension and Rural Development and the Institute for Food, Nutrition and Well-being, University of Pretoria, South Africa, ${ }^{7}$ Malagasy Land Observatory, Madagascar, ${ }^{8}$ UMR LISIS (University of Paris-Est Marne la Valle), France, ${ }^{9}$ Centre for Training and Integrated Research in ASAL Development (CETRAD), Nanyuki, Kenya, ${ }^{10}$ Department of Plant and Soil Sciences, University of Pretoria, South Africa, ${ }^{11}$ Wyss Academy for Nature, University of Bern, Switzerland 
changes, and governance systems explain differences in LAIs' socio-economic, food security, and environmental impacts. It brings together results on these aspects generated in the AFGROLAND project. We studied LAIs in Kenya, Madagascar, and Mozambique. Primary data were collected using a mixedmethods approach combining large-scale household surveys, a survey of business models, semi-structured interviews, life-cycle assessment, remote-sensing data, and document analysis. The present synthesis of the AFGROLAND project was conducted through a collaborative expert workshop in combination with a set-theoretic methodology for case-based comparative analysis. Our study thus responds to calls for use of robust empirical methodologies to provide reliable evidence on the impacts of LAIs (Oya 2013, Scoones et al. 2013), as well as to calls for use of comparative methods to attribute LAI impacts to particular conditions (Purdon 2013, Meyfroidt 2016).

Two research questions guided our study. First, do LAIs in Kenya, Madagascar, and Mozambique exhibit recurring patterns of socio-economic, food security, and environmental impacts? Second, how are differences in business models, land use changes, and governance systems associated with variations in LAI impacts?

We find that the LAIs in our sample follow four distinctive impact patterns, ranging from widespread adverse impacts and hostility to moderate impacts. The following conditions jointly shape how common global drivers of land use change translate into different forms of LAIs and diverse impacts: labor intensity, prior land use, utilization of land, farm size, type of production, experience in local agriculture, land tenure security, accountability of state and local elites, the mobilization capacity of civil society, expansion of agricultural resource frontiers, agricultural intensification, and indirect land use change.

\section{CURRENT CONTROVERSIES AROUND LARGE-SCALE AGRICULTURAL INVESTMENTS}

Debates on LAIs have evolved over the past decade (Cotula 2009, Borras et al. 2011, De Schutter 2011, Borras and Franco 2012, White et al. 2012, D'Odorico et al. 2017). This section reviews current controversies that focus on LAI impacts, land use changes, business models, and governance. Large-scale agricultural investments include large-scale land acquisitions (LSLA) as well as capital-intensive agricultural investments. Large-scale land acquisitions encompass transfers of rights to use, control, or own land from smallholder households or communities to commercial actors (e.g., corporations, public investment funds) through sale, lease, or concession of areas larger than 200 ha (Anseeuw et al. 2013). Here, we extend this focus on LSLA by incorporating LAIs that are smaller in farm size, but large in invested capital, such as horticulture farms. This allows us to compare a broader range of farm sizes associated with corporate land investments.

Socio-economic Impacts of Large-scale Agricultural Investments Large-scale agricultural investments are commonly justified using development narratives that emphasize new opportunities for employment, agricultural productivity, and infrastructure in targeted regions (German et al. 2016, Zoomers and Otsuki 2017). Empirical case studies, by contrast, point to numerous adverse impacts of LAIs. Meta-analysis of case studies show that livelihood benefits for beneficiary households can indeed occur if LAIs generate decent employment (Oberlack et al. 2016, Hufe and Heuermann 2017). However, dominant narratives in Africa contend that LAIs rarely realize the employment effects initially anticipated (Li 2011, Deininger and Byerlee 2012, Palliere and Cochet, 2018). Labor conditions are criticized for low wages, poor working conditions, and short-term contracts (Li 2011). Evidence shows that levels of job creation and quality vary according to agricultural model, previous land use, and institutional contexts (Smalley 2013, Hakizimana et al. 2017, Hall et al. 2017, Nolte and Ostermeier 2017).

Loss of access to land and water is the most frequently reported adverse impact of LAIs on rural livelihoods (Oberlack et al. 2016). It occurs most directly when smallholders, pastoralists, or other land users are displaced by land concessions, leases, or purchases (Borras and Franco 2012). Land tenure insecurity is fueling these effects (Haller et al. 2019). Pro-LAI discourses often mobilize narratives of vacant, fallow, or unproductively used lands ( $\mathrm{Li}$ 2014, Scoones et al. 2019). However, global and local scientific evidence shows that land targeted for investment is already used by smallholders, pastoralists, or local entrepreneurs in the majority of cases (Alden Wily 2012, Messerli et al. 2014, Schoneveld and German 2014). Large-scale agricultural investments often exacerbate conflicts in target regions (Hufe and Heuermann 2017), not only between communities and investors but also between villages, families, and generations (Bottazzi et al. 2016, Millar 2016).

Thereby, LAIs can contribute to undermine resilience. Haller et al. (2020) introduced the notion of "resilience grabbing" to refer to processes in which LAIs reduce the resilience of local communities as a consequence of displacing them from access to food and non-food resources held as commons (Boillat and Bottazzi 2020).

Another subject of controversy is the distribution of LAI impacts, i.e., who bears the costs and who enjoys the benefits of such development (Peters 2013). Large-scale agricultural investments often marginalize already vulnerable groups, most frequently according to categories such as gender, ethnicity, prior poverty, and age (Schoneveld et al. 2011, Oberlack et al. 2016, Hall et al. 2017, Adams et al. 2018, Hajjar et al. 2019). Large-scale agricultural investment farms may employ vulnerable populations, but some of them may be too poor to decline low wages (Maertens and Swinnen 2009, Marfurt et al. 2016, Burnod et al. 2018). Finally, LAIs may be socio-economically harmful if jobs are transient, projects fail, or elites capture disproportionate shares of benefits (German et al. 2013, Nolte and Ostermeier 2017, Lanz et al. 2018).

Food Security Impacts of Large-scale Agricultural Investments Food security concerns are both a driver and an impact of LAIs. Here, we focus on the impacts of LAIs on the food security of households in LAI target regions. Limited empirical evidence exists on how LAIs impact household food security in Africa. Hufe and Heuermann's (2017) review of LAIs in Africa found that only four of 60 case studies (comprising 146 acquisition projects in 22 countries) exhibited harms to food security; however, the authors note that the cases fail to provide sufficient insight into the underlying mechanisms behind the effects of LAIs on food security. Large-scale agricultural investments may impact food security via changes in employment and land access. 
On the one hand, LAIs can improve food security by generating income opportunities in the agricultural, non-agricultural, and service sectors, based on new contracting or outgrower prospects, land leasing opportunities, increased local food supplies, or improved market access in remote areas (von Braun and MeinzenDick 2009, De Schutter 2011, Cotula et al. 2014). However, this presupposes that households have good and stable access to local food markets and are sufficiently resilient to price shocks (Bottazzi et al. 2018). Notably, the productivity of large farms has been found to be lower than that of smaller farms in Ethiopia (Ali et al. 2017) and Malawi (Deininger and Xia 2018), possibly indicating fewer income opportunities on larger farms.

On the other hand, LAI-related loss of land access can undermine food security for households who rely on agriculture for subsistence or income (Cotula 2009, 2011, Ronald 2014, Shete and Rutten 2015). Large-scale agricultural investments can increase commercial pressures on land, raising the cost per unit and constraining or barring access to communal areas used for grazing of livestock, fishing, and foraging (De Schutter 2011, Hall et al. 2015a).

Environmental Impacts of Large-scale Agricultural Investments Several environmental impacts are associated with LAIs. They are often seen as harming water resources (Zaehringer et al. 2018b). Aims of securing water resources have been suggested as key drivers of LAIs (Breu et al. 2016, Dell'Angelo et al. 2018), thereby reducing water access for small-scale farmers (Tejada and Rist 2018). Large-scale agricultural investments can increase greenhouse gas emissions via deforestation and use of fertilizers and pesticides (Intergovernmental Panel on Climate Change (IPPC) 2006). If cultivation and other management practices are unsustainable, soils may degrade until profits disappear and production must expand elsewhere (Shete et al. 2016). Other important, but understudied, environmental impacts include onand off-site loss of natural vegetation and biodiversity, as well as chemical pollution of water and air resources (Dell'Angelo et al. 2017a). There is general concern that LAI-related practices of intensification - such as monoculture, irrigation, and agrochemical use - can amplify environmental degradation (Mekonnen et al. 2012, Muriithi and Yu 2015, Lanari et al. 2016, Di Matteo and Schoneveld 2016).

\section{Agricultural Investments, Resource Frontiers, and the Transformation of Land Systems}

Large-scale agricultural investments drive transformations in social-ecological systems when they transform the land use systems in targeted areas. This can happen in at least three key ways: expansion of agricultural resource frontiers; agricultural intensification; and indirect land use change (Eckert et al. 2018, Ingalls et al. 2018, Zaehringer et al. 2018a, Magliocca et al. 2019).

Expansion of agricultural resource frontiers refers to situations in which demand for resource appropriation and associated capital inflows drive growth of agricultural land use at the expense of forests, grasslands, and shrublands (Peluso and Lund 2011, Meyfroidt et al. 2018, Barbier 2020). Large-scale agricultural investments may drive frontier expansion by facilitating capital inflows and triggering conversion of forests, shrublands, or grasslands into plantations. Davis et al. (2015) identified LAIs as a key driver of deforestation in Cambodia. Global estimates suggest that $32-60 \%$ of LAIs between 2000 and 2015 targeted forestlands, shrublands, and grasslands, indicating trends of agricultural frontier expansion (Messerli et al. 2014, Nolte et al. 2016). Indeed, agricultural expansion remains the most important proximate driver of deforestation (Hosonuma et al. 2012, Ceddia et al. 2014), and expansion of large commercial farms often displaces prior land users (Meyfroidt et al. 2018).

Large-scale agricultural investments may foster agricultural intensification by increasing inputs per land unit, (monocrop) yields per land unit, or the density of a resource system (Eckert et al. 2018, Meyfroidt et al. 2018). Such intensification can trigger additional agricultural expansion, especially if effective environmental governance is absent (Ceddia et al. 2014). Largescale agricultural investments often create large-scale capitalized agriculture in areas where smallholders previously dominated agrarian sectors. Yet most assessments of agricultural intensification fail to ask: "Intensification for whom?" Displaced smallholders may either out-migrate, relocate land use to adjacent areas, or accept employment on LAI farms (Tejada and Rist 2018).

Large-scale agricultural investments lead to indirect land use changes (iLUC) by displacing land uses elsewhere at the cost of other land cover or land use in these areas (Bergtold et al. 2017, Zaehringer et al. 2018a, Magliocca et al. 2019). Large-scale agricultural investments can trigger iLUCs in several ways. First, displaced smallholders seeking cheaper or forested land in an LAI's target region can induce additional, off-site agricultural expansion (Meyfroidt et al. 2018). Second, LAIs may trigger iLUC via transfer of knowledge and technologies from LAI farms to small-scale farms. One example is adoption of agricultural practices on small farms neighboring LAI farms. Nevertheless, evidence of such spillovers is limited (Deininger and Xia 2016). Finally, LAIs may induce iLUC when seasonal workers on LAI farms encroach on adjacent areas seeking additional livelihood options beyond on-farm employment (Tejada and Rist 2018).

\section{The Organization of Agricultural Investment and Production through Large-scale Agricultural Investments}

Business models are the organizational strategies and governance structures that determine how a firm organizes its agricultural investment, production, and trade activities (Chamberlain and Anseeuw 2018). Boche and Anseeuw (2014) identified independent farmers, cooperatives, speculative enterprises, contract farming, and agribusiness as the main business models active in southern African LAI contexts. Common trends include high investment failure rates, tendencies to increase value-chain integration, and lacking inclusiveness of local populations. Poor operational performance of LAIs has been repeatedly observed in different parts of the world, including Laos (Schoenweger and Messerli 2015), Madagascar (Burnod and Andriamanalina 2017), and across Africa (Cotula et al. 2014, Hall et al. 2015a).

Earlier research has identified the following business-model features as key to LAI evolution and impact: (1) type of actor, (2) degree of vertical integration, (3) origin of capital, (4) juridical form, (5) main production, (6) organization of agricultural production mode, (7) technical agricultural model, and (8) ways of accessing land (Camisón and Villar-López 2010, Boche and Anseeuw 2014, Chamberlain and Anseeuw 2017). 
Although many LAIs commodify land and labor (D'Odorico et al. 2017), certain inclusive business models may comprise more decommodified forms of social exchange (Haller et al. 2016, Gerber and Gerber 2017). Inclusive business models are possible alternatives for structuring agricultural investments. Instead of land acquisitions, they may rely on collaborative arrangements between capitalized investors and small-scale farmers and communities (Vermeulen and Cotula 2010). No single model, however, has been identified as the best option for smallholders in all circumstances, and none reviewed can be said to be perfectly fair or offering a holistic solution to rural development at local and national levels (Lahiff et al. 2012, Cramb 2013, Chamberlain and Anseeuw 2017).

\section{Governance of Large-scale Agricultural Investments}

Governance of LAIs encompasses numerous actors spanning many different levels of activity, ranging from community-based collective action to state-based decision making and global governance (Margulis et al. 2013, Oberlack et al. 2018). Important mechanisms to regulate and shape LAIs include legal regulations and human rights provisions (Schoneveld and German 2014, Bürgi 2015, Nolte and Väth 2015, Schoneveld 2017), voluntary guidelines (Seufert 2013), transparency initiatives (Vijge et al. 2019), and social movements (Hall et al. 2015b). Here, we focus on how global/national agricultural policy and land policy mediate the influence of global drivers of LAIs, shaping implementation of LAIs and their impacts on the ground.

Globally, the agricultural policy debate has been marked by proliferation of multi-actor platforms, some of which promote LAIs in Africa (High Level Panel of Experts on Food Security and Nutrition (HLPE) 2018). The latter have fostered narratives of untapped land potential in Africa and the need to produce more food. These narratives point to the increasing role of transnational corporations in global food security (Fouilleux et al. 2017). In the aftermath of the global food price crisis of 20072008, the G8 heads of state/government made food security a priority in L'Aquila in 2009 (Margulis 2012). Several initiatives followed. For instance, the African Union Commission, the New Partnership for Africa's Development (NEPAD), and the World Economic Forum founded Grow Africa in 2011 with the aim of increasing private sector investment in agriculture. The New Alliance for Food Security and Nutrition (NAFSN), formally established in 2012, brings together 10 African governments, the African Union, private-sector actors, and donors to encourage private investment in agriculture (McKeon 2014).

In the global land policy field, diverse voluntary arrangements are meant to govern LAIs. The Principles for Responsible Agricultural Investment that Respects Rights, Livelihoods and Resources (PRAI) were endorsed by the World Bank, the United Nations Conference on Trade and Development (UNCTAD), FAO, and International Fund for Agricultural Development (IFAD) in 2010-2011. The seven principles encompass all types of investment in agriculture, including between principal investors and contract farmers. They are intended to provide a framework without constraining power to guide and assess national regulations, international investment agreements, corporate social responsibility initiatives, and individual investor contracts. In response to pressure by international civil society organizations for tighter principles, the Committee on World
Food Security endorsed the Voluntary Guidelines on the Governance of Tenure to Land, Forests and Fisheries (VGGT) in 2012 (Seufert 2013).

In countries under an aid regime like Madagascar, Mozambique, and, to a lesser extent, Kenya, external actors such as bi- and multi-lateral cooperation agencies, international non-governmental organizations (NGOs), and private foundations often shape the development of public policies (Lavigne Delville 2017). This external influence may operate, for instance, by conditioning national budget support, institution building, and public policy transfers. International actors often directly shape the policy discourse and instruments produced by national governments. Yet countries that are comparable in terms of aid dependency and history do not always make the same policy choices. Portrayals of top-down land grabs often overlook the agency of host states and domestic elites at the national and local level (Fairbairn 2013, Wolford et al. 2013, Lanz et al. 2018). Similarly, in countries with elaborate legal provisions to protect customary tenure, national/ local enforcement of said rules remains key to safeguard land tenure and access effectively (German et al. 2013, Haller et al. 2016, Delaney et al. 2018). Indeed, the interplay of policy and legal frameworks with national/local human agency may be one of the most decisive factors shaping LAI implementation and impacts (Nolte and Väth 2015, Lundsgaard-Hansen et al. 2018).

Large-scale agricultural investments are frequently contested by NGOs and others on the ground (Temper et al. 2015). The mobilization capacities of local, national, and international NGOs vary. Some NGOs simply act as intermediaries informing and explaining the situation and possibilities to local communities, whereas others act as spokespersons and defend a specific cause in national or international arenas (Tafon and Saunders 2019). These strategies are more effective when they are echoed by traditional authorities, local groups, the media, and diplomatic actors (Allaverdian 2010, Rocheleau 2015, Lavers and Boamah 2016). The implementation of particular land and agriculture policies may depend on the mobilization capacity of local and national civil society as well as on the views of national elites influenced by their relationships with the donor community and past experiences with investors.

Taken together, one important frontier in the debate on LAIs relates to deeper understanding of the interactions and variations among the socio-economic, food security, and environmental impacts of LAIs. A second frontier calls to clarify the role and interactions of business models, governance, and land-use changes in translating common global drivers of land investments into varying impacts on the ground. Addressing these frontiers requires methodological approaches of cross-country comparative analyses of LAIs that use consistent interdisciplinary research instruments. The AFGROLAND project has set out to contribute to push these frontiers.

\section{MATERIALS AND METHODS}

\section{Research Design}

This paper combines a collaborative expert workshop with a casebased comparative analysis to synthesize results of the AFGROLAND project. It brings together the results of specialized research questions on land use change, business 
models, governance systems, as well as socio-economic, food security, and environmental impacts (Burnod and Andriamanalina 2017, Bourblanc and Belenfant 2018, Burnod et al. 2018, da Silva 2018, Eckert et al. 2018, Giger et al. 2018, 2020, Mawoko et al. 2018, Fitawek 2019; Adalima, unpublished manuscript; Burnod, unpublished manuscript; Masola et al., unpublished manuscript; Mutea et al., unpublished manuscript; Ralandison, unpublished manuscript, Reys et al., unpublished manuscripts) by examining the recurrent patterns and linkages between these aspects.

We chose a set-theoretic methodology for our comparative analysis (Schneider and Wagemann 2012). This methodology enabled integration of quantitative and qualitative data, matched our sample size, and fit our ambition of identifying contextsensitive generalizations that explain how particular outcomes/ impacts of LAIs relate to different combinations of conditions (i.e., equifinality) (Magliocca et al. 2018, Oberlack et al. 2019, Eisenack et al. 2019).

Kenya, Madagascar, and Mozambique were selected as study countries because they: (1) experienced a rush of LAIs in the past two decades; (2) belong to the same regional economic community and bear similarities in regional trade and economic policies; and (3) vary in the degree of commercialization of their agrarian sectors. Mozambique features intermediate development of commercial agriculture (compared with Kenya and Madagascar) and has recently experienced many LAIs via the Beira and Nacala development corridors. Kenya is a well-integrated economy with a comparatively mature commercial agriculture sector. And Madagascar features a comparatively fragile governance system with a relatively easily influenced political-economic situationit is known for many attempted land deals, most of which have failed.

In each country, we identified regional hotspots of LAIs in which to analyze LAI dynamics beyond individual cases: the Nanyuki area of Kenya (in Laikipia County), the highlands of Madagascar, and the Nacala Corridor of Mozambique (Monapo und Gurué districts). For the present synthesis, we included 16 LAIs according to the following criteria: (i) range of mature and recent investments; (ii) range of business models; and (iii) availability of data from multiple work packages for the project synthesis. ${ }^{1}$ Five cases are in Kenya, three in Madagascar, and eight in Mozambique. In Kenya, we chose cases in an area that is typical for the relatively mature and intensive type of investments, which characterize an important part of the agricultural sector in Kenya (Eckert et al. 2018, Giger et al. 2020). In Mozambique, we chose relatively large-scale land acquisitions in the Nacala corridor, which is one of six corridors designated by the government as priority areas to foster agricultural growth through large-scale land investments (Ikegami 2015). In Madagascar - despite a wave of announced land acquisitions after 2005-by 2015, out of 85 cases, more than $90 \%$ had failed. We finally chose two of the very few remaining and operational cases in the country and one failed case, located in Central Madagascar (Burnod and Andriamanalina 2017).

\section{Data Collection and Data Analysis}

Using a mixed-methods approach, the AFGROLAND project combined six methods to collect primary data in 2015-2017 (Poteete et al. 2010). (1) Three rural household surveys using stratified random samples in Mozambique $(n=504)$, Kenya $(n=$
545), and Madagascar $(n=601)$-i.e. 1,650 households in total -capture socio-economic and food security impacts of LAIs. To assess impacts, we compared engaged households (i.e., employed directly or contract farming), non-engaged households in a LAI target area, and households in counterfactual areas without LAIs (Reys et al., unpublished manuscripts). (2) We conducted 296 semistructured household interviews with open-ended questions (99 in Kenya, 96 in Madagascar, and 101 in Mozambique) to record household perceptions of land use changes, environmental impacts, and conflicts (Zaehringer et al. 2018a, b). (3) We conducted 12 semi-structured interviews (four in Kenya, eight in Mozambique) with LAI representatives and 20 interviews with small-scale farmers (10 in Kenya, 10 in Mozambique), and completed life-cycle assessments, including water footprint assessments, to measure environmental impacts (da Silva 2018). (4) We analyzed remote-sensing data to quantify land uses and land use changes in the study areas (Eckert et al. 2018, Zaehringer et al. 2018a). (5) We conducted 68 semi-structured interviews with investors to survey business models (Adalima, 2016, unpublished manuscript, Burnod, 2017, unpublished manuscript, Mutea et al., 2017, unpublished manuscript). Finally, (6) we conducted key informant interviews with representatives from public and governmental organizations, development and finance organizations, project managers, farmer organizations, civil society and the private sector, and performed document analysis to collect data on governance systems (Burnod and Andriamanalina 2017, Bourblanc and Belenfant 2018; Ralandison, 2016, unpublished manuscript, Burnod, 2017, unpublished manuscript). For the present project synthesis, we used these data and analyses in a collaborative expert workshop and for the truth table of our settheoretic comparative analysis. The research protocol of the present project synthesis followed six main steps (Fig. 1).

Step 1. Collaborative expert workshop

The expert workshop with 19 project members from six countries was held at the University of Pretoria, South Africa, in January 2018. Project members presented and discussed the results of the individual work packages; created a common understanding of the main results; identified the indicators for synthesis; and discussed the relationships between business models, land use changes, governance systems, as well as socio-economic, food security, and environmental impacts of LAIs.

\section{Step 2. Identify indicators}

We characterize the main categories of interest in this synthesis through 103 indicators, including 6 indicators for socioeconomic impacts, 7 for food security impact, 14 for environmental impacts, 21 for business models, 33 for land use changes, 17 for governance systems, and 5 for social-ecological contexts. Table A1 in the Append. 1 provides the details of their measurement scale and data sources. We decided that the main unit of analysis for the synthesis would be the scale of LAIs and their adjacent zones of influence ( $5 \mathrm{~km}$ around an LAI), as this is where most of the direct impacts occur.

\section{Step 3. Compile database and truthtable}

We compiled the data set for the present synthesis by characterizing each of the 16 included LAIs along the 103 indicators by merging data from the individual work packages of the AFGROLAND project. Next, we converted this data into a truth table, indicating the presence or absence of an attribute for 
Fig. 1. Research protocol.

\begin{tabular}{|c|c|c|}
\hline Step & Activity and method & Result \\
\hline $\begin{array}{l}\text { 0. Primary data } \\
\text { collection and } \\
\text { analysis }\end{array}$ & $\begin{array}{l}\text { Mixed-methods approach in four work packages of the AFGROLAND project, } \\
\text { including: household surveys ( } \mathrm{n}=1,650) \text {, semi-structured interviews with } \\
\text { investors ( } \mathrm{n}=68+12) \text {, semi-structured interviews with households }(\mathrm{n}=328+20 \text { ), } \\
\text { life-cycle assessment, remote-sensing data analysis, key-informant interviews } \\
\text { and document analysis in Kenya, Madagascar, and Mozambique in 2015-2017. }\end{array}$ & $\begin{array}{l}\text { In-depth results on business models, } \\
\text { land use changes, governance } \\
\text { systems, socio-economic, food } \\
\text { security and environmental impacts } \\
\text { (cf. references in text). }\end{array}$ \\
\hline \multicolumn{3}{|c|}{-1} \\
\hline $\begin{array}{l}\text { 1. Collaborative } \\
\text { expert workshop }\end{array}$ & $\begin{array}{l}\text { A collaborative workshop of } 19 \text { project members from six countries was held } \\
\text { at the University of Pretoria, South Africa, in January 2018. It enabled project } \\
\text { members to present and discuss the results of the individual work packages; to } \\
\text { create a common understanding of the main results; to begin identifying the } \\
\text { indicators for overall synthesis; and to discuss relations between business } \\
\text { models, land use changes, governance systems, as well as the socio-economic, } \\
\text { food security, and environmental impacts of LAIs in a qualitative manner. }\end{array}$ & $\begin{array}{l}\text { Shared understanding among project } \\
\text { members of main results from the } \\
\text { four work packages; co-design of } \\
\text { synthesis work; indicators. }\end{array}$ \\
\hline \multicolumn{3}{|c|}{ 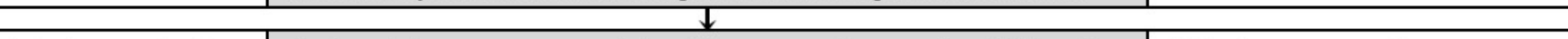 } \\
\hline 2. Indicator selection & $\begin{array}{l}\text { At the collaborative expert workshop (University of Pretoria, Jan. 2018) and } \\
\text { subsequent refinement, identifying the main indicators of each work package. }\end{array}$ & 103 indicators in total \\
\hline \multicolumn{3}{|c|}{ 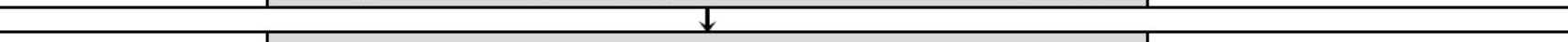 } \\
\hline 3. Common database & $\begin{array}{l}\text { Compilation of primary data in common database and standardization of data } \\
\text { into a truth table for Formal Concept Analysis. }\end{array}$ & $\begin{array}{l}\text { Truth table with } 103 \text { indicators for } \\
\text { 16 LAIs. }\end{array}$ \\
\hline \multicolumn{3}{|c|}{$\downarrow$} \\
\hline $\begin{array}{l}\text { 4. Identify impact } \\
\text { patterns }\end{array}$ & $\begin{array}{l}\text { Partitioning of impact profiles of the set of } 16 \text { LAIs. Criteria for partitioning: } \\
\text { the resulting stubsets are (1) consistent (i.e. assembling cases with similar } \\
\text { configurations of impact values); (2) crisp (i.e. cases of one subset are as similar } \\
\text { as possible among each other and as different as possible from other subsets); } \\
\text { (3) parsimonious (i.e. number of subsets as small as possible); ( } 4 \text { ) recurrent (i.e. } \\
\text { subsets observable in at least two cases); (5) and high coverage (the typology of } \\
\text { subsets covers all cases). }\end{array}$ & $\begin{array}{l}\text { - Four distinct and recurrent impact } \\
\text { patterns identified. } \\
\text { - Quantitative and qualitative } \\
\text { description of each impact pattern. }\end{array}$ \\
\hline \\
\hline $\begin{array}{l}\text { 5. Identify conditions } \\
\text { associated with each } \\
\text { impact pattern }\end{array}$ & $\begin{array}{l}\text { Using Formal Concept Analysis to identify the conditions of land use changes, } \\
\text { business models, governance systems and social-ecological contexts that that } \\
\text { are associated in a fully consistent }(100 \%) \text { and recurrent }(n \geq 2) \text { manner with } \\
\text { each impact pattern. }\end{array}$ & $\begin{array}{l}\text { - Consistent and recurrent } \\
\text { conditions for each impact pattern } \\
\text { identified. } \\
\text { - Quantitative and qualitative } \\
\text { description of all conditions. }\end{array}$ \\
\hline \\
\hline $\begin{array}{l}\text { 6. Verification and } \\
\text { interpretation }\end{array}$ & $\begin{array}{l}\text { Verification through cross-checking with results and expert knowledge of the } \\
\text { contributing researchers. Interpretation of results in view of current } \\
\text { controversies and hypotheses on LAIs. }\end{array}$ & $\begin{array}{l}\text { - FCA results verified against } \\
\text { primary sources and expert } \\
\text { understanding. } \\
\text { - Implications of results for } \\
\text { controversies on LAIs drawn. }\end{array}$ \\
\hline
\end{tabular}

each case. Table A1 and Append. 2 present the detailed methods used to compile the truth table (Append. 3). This truth table was the input for the set-theoretic comparative analysis (Rudel 2008, Schneider and Wagemann 2012).

\section{Step 4. Data analysis: identify the impact patterns}

To analyze this data, we applied Formal Concept Analysis (FCA) in search of recurrent impacts of LAIs and the associated conditions. Formal concept analysis is a tool for qualitative knowledge representation and inference (Ganter and Wille 2012). It is suited for set-theoretic comparative analyses as it identifies the multiple configurations of attributes present in the truth table. In contrast to qualitative comparative analysis (QCA) (Ragin 1987), FCA retains factors even if their presence and absence has led to the same outcome in different cases. We used the Concept Explorer software, with the truth table of cases and their attributes serving as our input. Formal concept analysis generates a concept lattice and compiles logical implications between attributes. "The concept lattice organizes the attributes in a hierarchical structure such that higher-tier attributes are logical implications of lower-tier attributes, while lower-tier items show distinct combinations with higher-tier attributes in the dataset" (Oberlack et al. 2016: 157). In this way, FCA is capable of visualizing multiple configurations of LAI impacts. To identify these patterns in the 27 indicators of socio-economic, environmental, and food security impacts, we identified distinct sets of impacts profiles among the 16 LAIs using the following criteria: the sets of impact profiles are (1) consistent (i.e., assembling cases with similar configurations of impact values); (2) crisp (where cases in one subset are as similar as possible to each other and as different as possible from cases in other subsets); (3) parsimonious (where the number of subsets is as small as possible); (4) recurrent (observable in at least two cases); (5) and have a high coverage (where the typology of subsets covers all cases). We first partitioned the cases based on the degree of households' losses of access to land, given the significance of land access for the 
impacts of LAI. This yielded subsets of cases with similar degrees of land access losses. Next, we noted all impacts that were consistently co-occurring in the cases of a given subset. Finally, we identified distinctive patterns within a subset, if more than two cases within this subset were similar on a particular impact indicator while being distinctively different to all other cases of the subset. This procedure resulted in four impact patterns.

\section{Step 5. Identify the processes and conditions consistently associated with each impact pattern}

We used FCA to identify the processes and conditions of land use changes, business models, governance systems, and socialecological contexts that are associated in a fully consistent $(100 \%)$ and recurrent $(n \geq 2)$ manner with each of the four impact patterns. Furthermore, we identified those conditions that hold for all but one case per impact pattern to correct for possible loss of information via the conversion of primary data into our truth table (i.e., standardizing numerical into categorical data for indicators with numerical measurement scale). Solely in instances where the attribute values of the unrepresented case were close $(+/-20 \%)$ to the values of the represented cases, we added those conditions to the set of consistent attributes. We noted the precise numeric values rather than the values of standardized classes for all processes/conditions identified in this manner.

Step 6. Verification

Finally, we verified the FCA results by crosschecking them with the results of the research teams of the individual work packages.

\section{Limitations}

The following limitations must be considered when interpreting our results. First, the data set involves missing data, as we do not have full data on all 103 indicators for all 16 cases - mostly regarding the Mozambican cases. The set-theoretic methodology of FCA helps address such gaps, as FCA provides robust results regarding distinct patterns even when data are missing. Formal concept analysis identifies similarities across cases without the need to impute missing data. More complete data might have added empirical support for the four patterns we found, or it may have enabled identification of additional patterns or more detailed sub-patterns within the four patterns. The missing data do not compromise the existing similarities we found in the available data set.

Second, some prior residents of the LAI target areas under analysis may have already out-migrated and been missed by the livelihood and food security surveys and household interviews. The household surveys and interviews captured residents living in the study areas at the time of fieldwork in 2015-2017. We cannot rule out that some households who lost land access to LAIs left the targeted area before survey/interview data were collected. Current residents, including in-migrants, may not always report on displacements that affected previous land users.

Third, we used 14 indicators to assess environmental impacts. Half of our data on environmental impacts (indicators ENV1-7) are based on the perceptions of households at the time of research. Perceptions of environmental impacts can be biased according to personal experiences and values. The other half of our data on environmental impacts (indicators ENV11-17) is based on interviews with LAI and small-scale farmers, corresponding with life-cycle assessments and expert assessments. Measuring and comparing environmental impacts across such diverse landscapes is challenging. In our case, quantitative data on indicators ENV11-17 were very scarce, or LAIs were unwilling to share them. This forced us to work with limited data and to use expert knowledge to fill in gaps on environmental impacts ENV11-17 (see Append. 2).

Finally, our conflict indicator is based on semi-structured interviews with open-ended questions with households (Zaehringer et al. 2018a, b). Therefore, we were able to capture a range of different kinds of interpretations of conflicts. Respondents mainly referred to overt acts of resistance and individual negative feelings toward the LAI. By contrast, covert acts of resistance are not captured. Therefore, the level of conflicts might possibly be underestimated by our indicator.

\section{RESULTS}

Part one of the results shows that the 16 LAIs follow four patterns exhibiting distinct impact profiles. The patterns are: (1) moderate employment with no loss of smallholder land access, but high conflict incidence and large environmental impacts (termed "conflicted neighborhood"); (2) moderate employment with no loss of smallholder land access, low conflict incidence, and low environmental impacts ("moderate neighborhood"); (3) large employment effects but at considerable cost to smallholder land access and the environment ("land loss to main employer"); and (4) widespread loss of land access, high conflict incidence, and negative attitudes ("widespread hostility"). Table 1 presents the descriptive statistics for each pattern for all socio-economic, food security, and environmental impact indicators. Figure 2 visualizes these profiles, and Fig. 3 illustrates the differences across patterns.

The second part of the results shows how particular processes and conditions of land use change, business models, and governance are associated consistently and recurrently with each impact pattern (Table 2). Each pattern is described below.

\section{Pattern 1: Conflicted Neighborhood: Moderate Employment, No Smallholder Land Access Loss, and High Conflict Incidence}

Socio-economic, food security, and environmental impacts Pattern 1 was exhibited by four LAIs, all in Kenya. Residents did not report any loss of access to land ( $0 \%$ of households), but $54 \%$ of households in the areas surrounding LAIs reported incidences of conflict. The reported tensions related to perceived air pollution (40-70\% of households in all four LAIs), chemical exposure $(35 \%$ of households affected by one LAI), and water pollution $(25 \%$ affected by one LAI). Similarly, water consumption, energy consumption, pesticide use, eutrophication potential, acidification potential, and global warming potential are highest in the LAIs of Pattern 1 (out of all the LAIs in our sample). Additionally, conflicts with pastoralists are not uncommon in the Nanyuki area, as reported by LAI farm managers and other stakeholders. Although the farms engage in water resource user associations (WRUAs), not all WRUAs were able to regulate water access comprehensively, and commercial farms in the WRUAs were found to have more bargaining power to access water than smallholder farmers (Jacobi et al. 2018, Ngutu et al. 2018). Despite the conflicts, relatively few households ( $24 \%$ on average) expressed wishes for the farms to leave the area. 
Table 1. Impacts of LAIs follow one of four patterns

\begin{tabular}{|c|c|c|c|c|}
\hline Impacts [measurement scale] & $\begin{array}{l}\text { Impact Pattern } \\
\text { (1) Conflicted } \\
\text { neighborhood }\end{array}$ & $\begin{array}{l}\text { (2) Moderate } \\
\text { neighborhood }\end{array}$ & $\begin{array}{l}\text { (3) Land loss to main } \\
\text { employer }\end{array}$ & (4) Widespread hostility \\
\hline Socio-economic impacts & \multicolumn{4}{|c|}{ Means (range), median } \\
\hline $\begin{array}{l}\text { Land access loss }[\%] \S, \mid \\
\text { Employment on-site }[\%] \S, \mid \\
\text { Preference for LAIs to leave }[\%] \S \\
\text { Conflict incidence }[\%] \S \\
\text { Infrastructure establishment }[\%] \S \\
\end{array}$ & $\begin{array}{l}0(0), 0 \\
15(8-26), 12 \\
24(15-30), 25 \\
54(35-65), 58 \\
15(0-35), 13 \\
\end{array}$ & $\begin{array}{l}0(0), 0 \\
8(6-10), 8^{\dagger} \\
10(0-24), 5 \\
11(4-20), 8 \\
53(0-80), 80 \\
\end{array}$ & $\begin{array}{l}26(22-29), 26 \\
65(63-67), 65 \\
- \\
- \\
-\end{array}$ & $\begin{array}{l}54(25-79), 46 \\
28(19-36), 28^{\ddagger} \\
60(20-85), 65 \\
68(18-95), 80 \\
44(0-89), 29 \\
\end{array}$ \\
\hline Food security impacts & \multicolumn{4}{|c|}{$\begin{array}{l}\text { Comparison of engaged households (EN), non-engaged households (NE) and households in } \\
\text { counterfactual areas (CF) }\end{array}$} \\
\hline $\begin{array}{l}\text { Food consumption } \\
\text { [relation of EN/CF and EN/NE] | } \\
\text { Household dietary diversity } \\
\text { [relation of EN/CF and EN/NE] | } \\
\text { Women's dietary diversity } \\
\text { [relation of EN/CF and EN/NE] | } \\
\text { Assets } \\
\text { [relation of EN/CF and EN/NE] | } \\
\text { Food provision } \\
\text { [relation of EN/CF and EN/NE] | } \\
\text { Coping strategies } \\
\text { [relation of EN/CF and EN/NE] | } \\
\text { Food security index } \\
\text { [relation of EN/CF and EN/NE] | }\end{array}$ & $\begin{array}{l}\mathrm{EN}>\mathrm{CF} \\
\mathrm{EN}>\mathrm{NE} \\
\mathrm{EN} \sim \mathrm{CF} \\
\mathrm{EN}>\mathrm{NE} \\
\mathrm{EN}<\mathrm{CF} \\
\mathrm{EN} \downarrow \mathrm{NE} \\
\mathrm{EN}>\mathrm{CF} \\
\mathrm{EN}>\mathrm{NE} \\
\mathrm{EN}>\mathrm{CF} \\
\mathrm{EN}>\mathrm{NE} \\
\mathrm{EN} \downarrow \mathrm{CF} \\
\mathrm{EN} \downarrow \mathrm{NE} \\
\mathrm{EN}>\mathrm{CF} \\
\mathrm{EN}>\mathrm{NE}\end{array}$ & $\begin{array}{l}\approx_{z^{\dagger}} \\
\mathrm{EN}^{\dagger}>\mathrm{NE}^{\dagger} \\
\approx \approx^{\dagger} \\
\mathrm{EN}^{\dagger}>\mathrm{NE}^{\dagger} \\
\approx \approx^{\dagger} \\
\approx \approx^{\dagger} \\
\mathrm{EN}>\mathrm{CF}^{\dagger} \\
\mathrm{EN}>\mathrm{NE}^{\dagger} \\
\mathrm{EN}>\mathrm{CF}^{\dagger} \\
\approx \approx^{\dagger} \\
\approx \approx^{\dagger} \\
\approx \approx^{\dagger} \\
\approx \approx^{\dagger} \\
\mathrm{EN}^{\dagger}>\mathrm{NE}^{\dagger}\end{array}$ & $\begin{array}{l}\mathrm{EN} \approx \mathrm{CF} \\
\mathrm{EN} \approx \mathrm{NE} \\
\approx \approx \\
\approx \approx \\
\approx \approx \\
\approx \approx \\
\mathrm{EN}>\mathrm{CF} \\
\approx \approx \\
\mathrm{EN}<\mathrm{CF} \\
\approx \approx \\
\mathrm{EN} \approx \mathrm{CF} \\
\mathrm{EN} \approx \mathrm{NE} \\
\approx \approx \\
\approx \approx\end{array}$ & 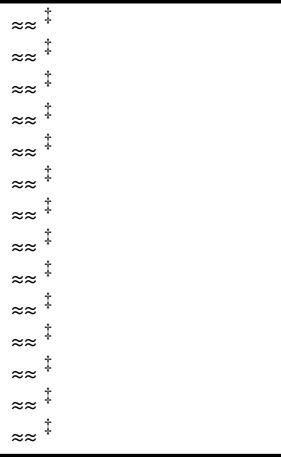 \\
\hline Environmental impacts & \multicolumn{4}{|c|}{ Means (range), median } \\
\hline 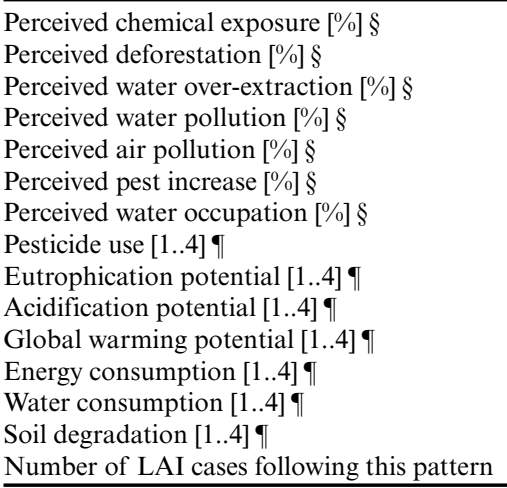 & $\begin{array}{l}13(5-35), 5 \\
1(0-5), 0 \\
9(5-25), 5 \\
6(0--15), 5 \\
53(40-70), 50 \\
13(5-25), 10 \\
0(0), 0 \\
3.8(3-4), 4.0 \\
3.8(3-4), 4.0 \\
3.8(3-4), 4.0 \\
3.8(3-4), 4.0 \\
3.8(3-4), 4.0 \\
3.8(3-4), 4.0 \\
3.0(3), 3.0 \\
4\end{array}$ & $\begin{array}{l}9(8-10), 9^{\dagger} \\
0(0), 0^{\dagger} \\
12(4-20), 12^{\dagger} \\
0(0), 0^{\dagger} \\
15(0-30), 15^{\dagger} \\
3(0-5), 3^{\dagger} \\
0(0), 0^{\dagger} \\
2.0(1-3), 2.0^{\dagger} \\
2.5(2-3), 2.5^{\dagger} \\
2.5(2-3), 2.5^{\dagger} \\
2.5(2-3), 2.5^{\dagger} \\
2.0(1-3), 2.0^{\dagger} \\
2.0(1-3), 2.0^{\dagger} \\
3.0(3), 3.0^{\dagger} \\
3\end{array}$ & $\begin{array}{l}- \\
- \\
- \\
- \\
- \\
- \\
- \\
1.5(1-2), 1.5 \\
2.0(1-3), 2.0 \\
2.0(1-3), 2.0 \\
1.5(1-2), 1.5 \\
2.0(1-3), 2.0 \\
1.5(1-2), 1.5 \\
3.0(2-4), 3.0 \\
2\end{array}$ & $\begin{array}{l}4(0-16), 0 \\
15(0-27), 5 \\
2(0-16), 0 \\
3(0-16), 0 \\
6(0-28), 0 \\
0(0), 0 \\
9(0-17), 9 \\
2.4(1-3), 3.0 \\
2.3(1-3), 2.0 \\
2.6(1-3), 3.0 \\
2.6(1-3), 3.0 \\
2.6(1-3), 3.0 \\
2.4(1-3), 3.0 \\
2.1(1-3), 2.0 \\
7\end{array}$ \\
\hline $\begin{array}{l}\text { Notation: EN: engaged households, N } \\
\text { food secure households and more most-food } \\
\text { households), } \approx \text { no difference, } \approx \approx \text { inconclu } \\
\text { three cases, }+ \text { data available for two of seve } \\
\text { WP4, I data source: household interviews, }\end{array}$ & $\begin{array}{l}\text {-engaged house } \\
\text { re households), } \\
\text { idence across ca } \\
\text { § data sourc } \\
\text { cle assessment, }\end{array}$ & $\begin{array}{l}\text { counterfactual } \\
\text { ion (less most- } \\
\text { not available, } \\
\text { interviews of } \\
\text { ssessment, }\end{array}$ & $\begin{array}{l}\text { than, < worse than, } \\
\text { households and less mo } \\
\text { ge of households, } \dagger \text { di } \\
\text { per case), | data sour }\end{array}$ & $\begin{array}{l}\text { spreading (more most- } \\
\text { t-food insecure } \\
\text { ta available for two of } \\
\text { : household survey of }\end{array}$ \\
\hline
\end{tabular}

The four farms have generated moderate employment effects, as $15 \%$ of households in their surroundings have at least one member employed by them. Many households in the area have built livelihoods based on jobs with other employers (40-65\%) as well as based on self-employment. This indicates that the four LAIs are but one livelihood option among several alternatives in the Nanyuki area. The food security situation of employed households tends to be slightly better than that of unemployed households in the LAI zones or households in the "counterfactual" zone. This is indicated by slightly better food consumption, better household dietary diversity, better assets, fewer months of inadequate food provision, and better food security index. However, the food security impacts are spreading in terms of women's dietary diversity and coping strategies. That means that, compared with both non-engaged households and households in the counterfactual area, more engaged households apply severe coping strategies such as skipping meals and more engaged households apply milder strategies such as borrowing food.

\section{Associated features of business models, governance, and land use changes}

All four LAIs of Pattern 1 share similar business model-related features. All are greenhouse-based horticulture farms in Kenya's Nanyuki area. At the time of research in 2017, they ranged in age from 4 to 17 years. Their operational farm size was moderately large - between 23 ha and 87 ha - and their acquired farm size ranged from 27 ha to 140 ha. Each created between 493 and 600 jobs. Their large labor intensity (6.9-20 jobs/ha) and land 
Fig. 2. Profiles of the four impact patterns. Note: the scale denotes the strength of the impact from 1 (no impact) to 4 (strong impact), with 0 (no data). It does not denote a judgement as to whether this impact is "good" or "bad".

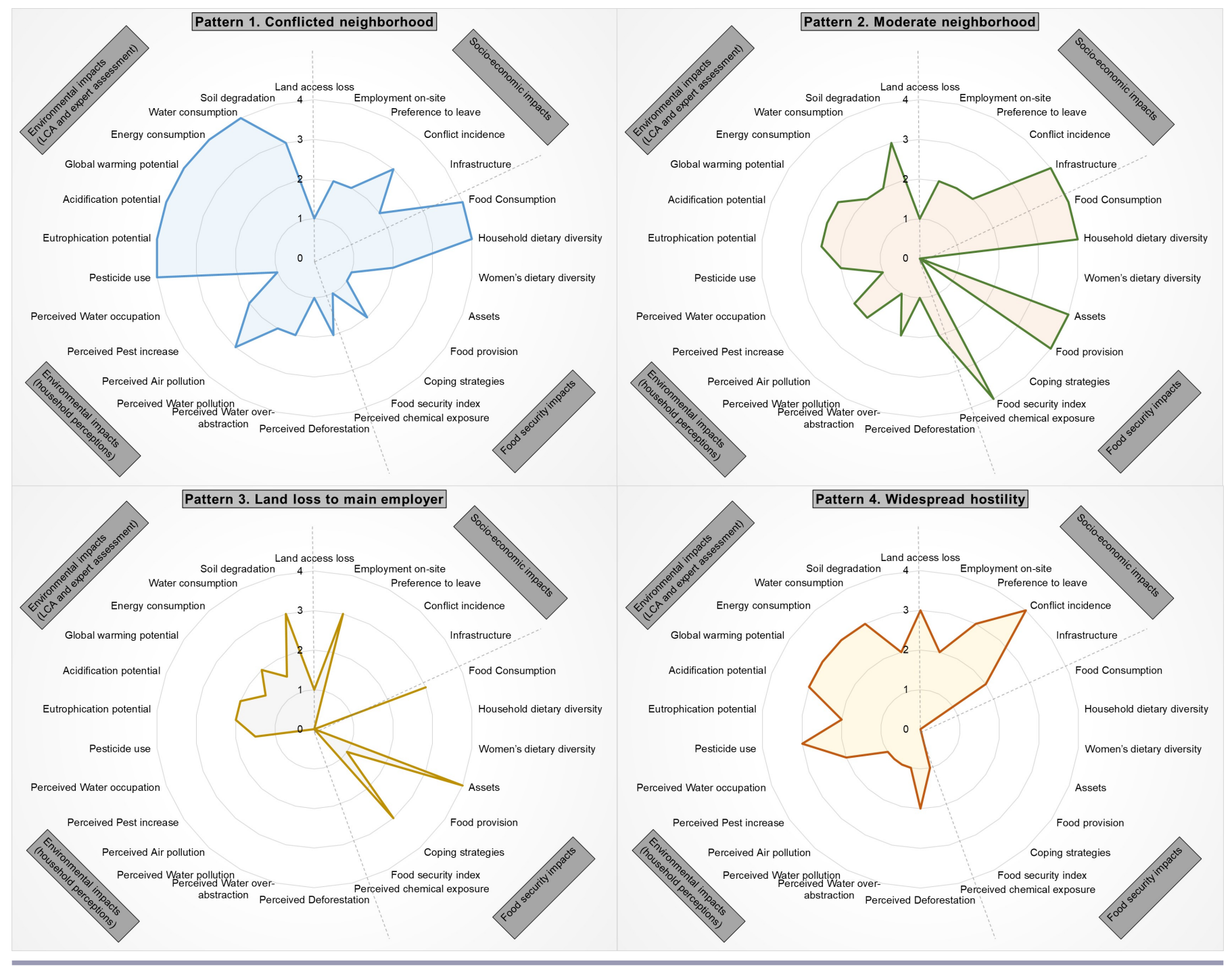

utilization rate $(62-100 \%$ of leased land actually used) were comparatively large. They recruited workers in adjacent areas and externally. Employment contracts were longer than 8 months for about $90 \%$ of workers, indicating low levels of daily/seasonal employment. Salaries were under USD \$2/day for $8 \%$ of employees, between USD $\$ 2$ and USD \$5/day for $60 \%$, and over USD \$5/day for $31 \%$ of employees.

All four LAIs were established on land used previously by large farms. They were owned either by domestic investors or those with experience in Nanyuki's local agricultural context.

All the LAIs intensified agricultural land use with high degrees of mechanization and input intensity. Three LAIs also involved agricultural expansion, but one did not. We found some evidence that LAIs triggered spillovers to land management on smallholder farms via extension services, outgrower contracts, and excessive extraction of water, spurring smallholders to modify their land management.
The governance system combines a policy discourse that is mildly favorable to LAIs with good mobilization capacity of civil society organizations (CSOs), strong land property rights, and high land tenure security for smallholders as well as a government whose accountability to smallholders is comparatively high.

\section{Pattern 2: Moderate Neighborhood: Moderate Employment, No Smallholder Land Access Loss, and Low Conflict Incidence}

Socio-economic, food security, and environmental impacts

Similar to pattern 1 , the three LAIs following Pattern 2 - one in Kenya and two in Madagascar - involved no loss of smallholder land access $(0 \%$ of households in adjacent areas) and featured moderate employment effects $(6-10 \%$ of households in adjacent areas). They also generated slightly positive effects for engaged households according to most food security indicators, when compared with non-engaged households in LAI target areas.

In contrast to Pattern 1, however, the LAIs of Pattern 2 exhibit lower incidences of conflict ( $4 \%, 8 \%$, and $20 \%$, respectively). They 
Fig. 3. Comparison of the four impact patterns.

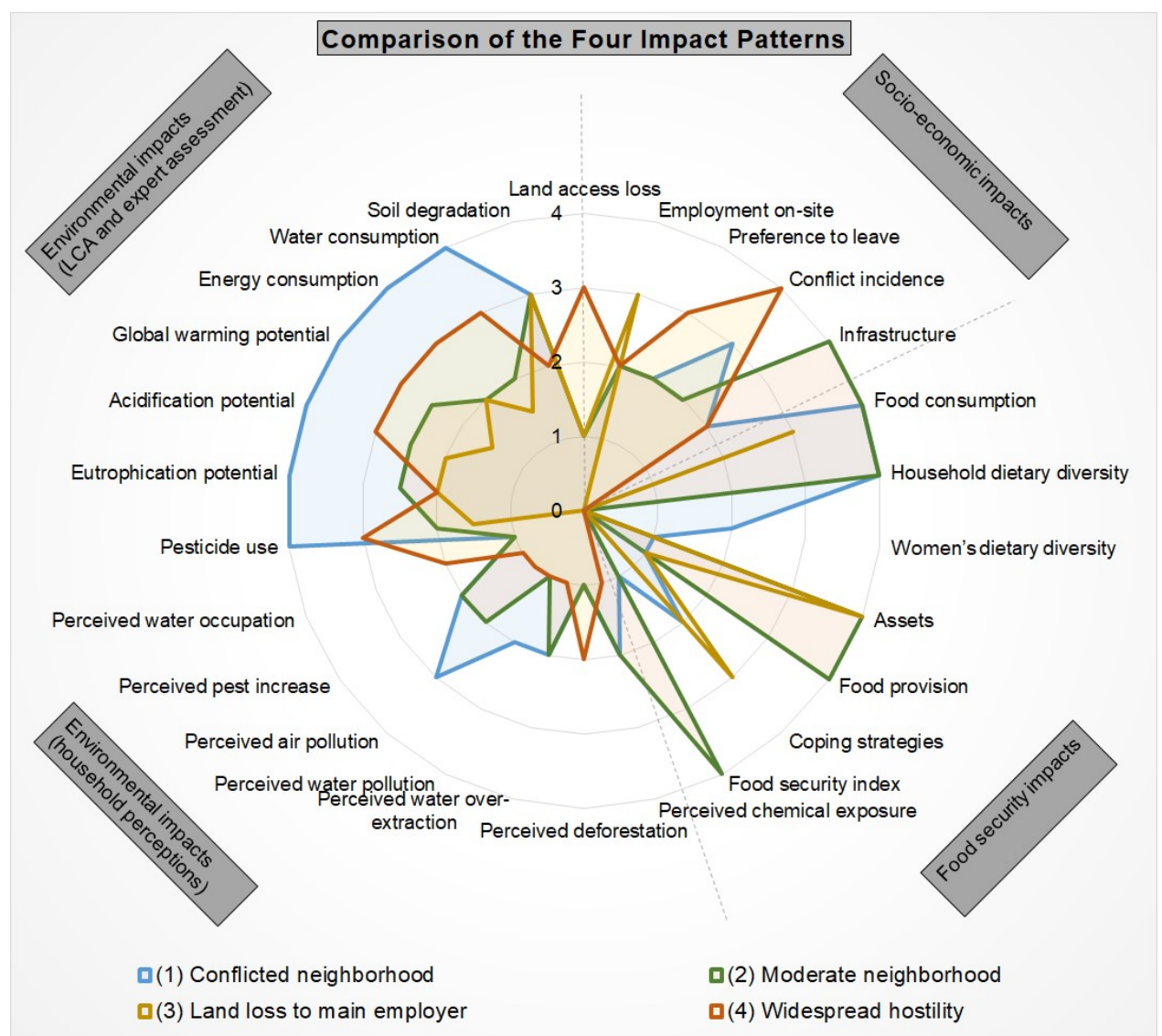

also feature less extreme environmental impacts. Furthermore, two of three LAIs following Pattern 2 exhibit widely perceived infrastructure benefits $(80 \%$ and $81 \%$ of affected households, respectively).

\section{Associated features of business models, governance, and land use changes}

The three LAIs following Impact Pattern 2 were characterized by two configurations of conditions. Two farms-one horticultural farm in Kenya and one barley contract-farming scheme in Madagascar - were moderate to large operational farm sizes (125 ha and 256 ha, respectively). The Kenyan farm was established 12 years prior to the time of research, whereas the Malagasy LAI farm was established 2 years prior. Both involved contract farming with smallholders, with the Kenyan farm also operating on its own fields. The two commercial farms engaged 850 and 2,636 persons, respectively (as employees or smallholders), making labor intensity comparatively high (6.8 and 10.3 jobs/ha). ${ }^{2}$

The third LAI featured different processes and conditions giving rise to a different impact pattern. It was a jatropha project in Madagascar that was abandoned shortly before the research. In 2008, it acquired 2,220 ha of land for implementation of a jatropha plantation. The investor was an international newcomer to the country's agricultural sector. The farm planted young jatropha trees on 600 ha of land previously used by pastoral communities as grazing land, substantially reducing available fodder for livestock. The project was abandoned in 2016, but the land is now legally registered in the name of the state. Beginning in 2017, we observed communities (via satellite imagery) resuming seasonal burning of their former grazing land, as was done for decades prior to arrival of the LAI.

\section{Pattern 3: Land Loss to Main Employer: Large Employment Effects vs. Smallholder Land Loss}

Socio-economic, food security, and environmental impacts

Impact Pattern 3 was displayed by two LAIs - both in Mozambique - that had become the main employer in their target region. Overall, $63 \%$ and $67 \%$ of nearby households, respectively, had at least one member employed by them. However, $22 \%$ and $29 \%$ of households, respectively, experienced loss of land access. Evidence on the food security situation was mixed. Compared with nonengaged and counterfactual households, the LAI-employed households had slightly better assets, similar food consumption and coping strategies, but worse food provision. Environmental impacts were moderate to high.

Associated features of business models, governance, and land use changes

The two LAIs operated large farms $(2,500$ ha and 3,000 ha, respectively). They included a sisal and a tea plantation with low degrees of mechanization and low-to-medium input intensity. They 
Ecology and Society 26(4): 18

Table 2. Processes and conditions of land use changes, business models, governance, and social-ecological contexts associated with each impact pattern

\begin{tabular}{|c|c|c|c|c|}
\hline \multirow{2}{*}{$\begin{array}{l}\text { Process or condition } \\
\text { [measurement scale] }\end{array}$} & \multicolumn{4}{|c|}{ Impact patterns } \\
\hline & 1 Conflicted neighborhood & 2 Moderate neighborhood & $\begin{array}{c}3 \text { Land loss to main } \\
\text { employer }\end{array}$ & 4 Widespread hostility \\
\hline \multicolumn{5}{|l|}{ Business model } \\
\hline$\overline{\text { Farm size operational [ha] }]^{\dagger}}$ & $\begin{array}{c}43^{\dagger} \\
(23-87)\end{array}$ & $\begin{array}{c}127^{\dagger} \\
(0-256)\end{array}$ & $\begin{array}{c}2750^{\dagger} \\
(2,500-3,000)\end{array}$ & $\begin{array}{c}1900^{\dagger} \\
(830-6,000)\end{array}$ \\
\hline Farm size acquired [ha] ${ }^{\dagger}$ & $\begin{array}{c}58^{\dagger} \\
(27-140)\end{array}$ & $\begin{array}{c}1260 \\
(300-2,220)^{*}\end{array}$ & $\begin{array}{c}5523 \\
(5,045-6,000)\end{array}$ & $\begin{array}{c}3974 \\
(850-10,000)\end{array}$ \\
\hline Utilization of land $[\%]^{\dagger}$ & $\begin{array}{c}84^{\dagger} \\
(62-100)\end{array}$ & $\begin{array}{c}21 \\
(0-42)^{\ddagger}\end{array}$ & $\begin{array}{c}51 \\
(42-60)\end{array}$ & $\begin{array}{c}61 \\
(15-98)\end{array}$ \\
\hline Workers total [number] ${ }^{\dagger}$ & $536^{\dagger}$ & $1162^{\dagger}$ & $1101^{\dagger}$ & $587^{\dagger}$ \\
\hline Labor intensity [workers/ha] ${ }^{\dagger}$ & $\begin{array}{c}(493-600) \\
15.2^{\dagger}\end{array}$ & $\begin{array}{c}(0-2,636) \\
5.7^{\dagger}\end{array}$ & $\begin{array}{c}(800-1,401) \\
0.4\end{array}$ & $\begin{array}{c}(148-556) \\
0.4^{\dagger}\end{array}$ \\
\hline Prior land use [small-scale farming, large-scale farming] ${ }^{\dagger}$ & $\begin{array}{c}(6.9-20) \\
\text { Large-scale farming }^{\dagger}\end{array}$ & $\begin{array}{l}(0-10.3) \\
\quad \approx \approx\end{array}$ & $\begin{array}{l}\quad(0.4-0.5) \\
\text { Large-scale farming }^{\dagger}\end{array}$ & $\begin{array}{c}(0.07-0.4 ; 1 \text { outlier: } 1.4) \\
\text { Small-scale farming }\end{array}$ \\
\hline Years since establishment [years] & $\begin{array}{c}11.0 \\
(4-17)\end{array}$ & $\begin{array}{c}7.7 \\
(2-12)\end{array}$ & $\begin{array}{c}18.5^{\dagger} \\
(16-21)\end{array}$ & $\begin{array}{l}6.3^{\dagger} \\
(4-8)\end{array}$ \\
\hline $\begin{array}{l}\text { Experience of investor in local agriculture OR domestic } \\
\text { investor }[0 / 1]^{\dagger}\end{array}$ & $1^{\dagger}$ & $\approx \approx$ & 1 & $\approx \approx^{\dagger}$ \\
\hline International investor and manager $[0 / 1]^{\dagger}$ & $\approx \approx$ & $\approx \approx$ & $\approx \approx$ & $1^{\dagger}$ \\
\hline Juridical structure & $\approx \approx$ & $\begin{array}{l}\text { Private without } \\
\text { shareholding }\end{array}$ & $\approx \approx$ & $\approx \approx$ \\
\hline Vertical integration $[1-4]$ & 2 & $\approx \approx$ & $\approx \approx$ & $\approx \approx$ \\
\hline Production [in-house, contract farming] & In-house & $\approx \approx$ & In-house & In-house \\
\hline Main market [local, national, international] & International & $\approx \approx$ & - & $\approx \approx$ \\
\hline Irrigation [drip, overhead] & Drip & $\approx \approx$ & - & - \\
\hline Investor land access [lease, purchase, inheritance, rent] & $\approx \approx$ & $\approx \approx$ & $\approx \approx$ & Lease \\
\hline Status of irrigation [full operation, struggling, failed] & Full operation & $\approx \approx$ & Full operation & Full operation \\
\hline Certified production $[0 / 1]$ & 1 & $\approx \approx$ & $\approx \approx$ & - \\
\hline \multicolumn{5}{|l|}{ Land use change } \\
\hline Agricultural intensification $[0 / 1]^{\dagger}$ & $1^{\dagger}$ & $\approx \approx$ & - & $\approx \approx$ \\
\hline Agricultural expansion $[0 / 1]$ & $\approx \approx$ & $\approx \approx$ & - & 1 \\
\hline ILUC: LAI drives smallholders into forest $[0 / 1]^{\dagger}$ & $0^{\dagger}$ & 0 & - & $\approx \approx$ \\
\hline $\begin{array}{l}\text { ILUC: LAI induce land management change on smallholder } \\
\text { fields [0/1 }]^{\dagger}\end{array}$ & $1^{\dagger}$ & $1^{\dagger}$ & - & - \\
\hline LAI mechanization [low, medium, high] & $\mathrm{High}^{\S}$ & $\approx \approx$ & Low & $\approx \approx$ \\
\hline LAI input intensity [low, medium, high] & High & - & $\approx \approx$ & $\approx \approx$ \\
\hline \multicolumn{5}{|l|}{ Governance system } \\
\hline Experience of policymakers with LAI [strong/weak] & Strong & $\approx \approx$ & Strong & Strong \\
\hline $\begin{array}{l}\text { Agrifood policy discourse [Strongly, mildly, not favorable for } \\
\text { LAI }^{\dagger}\end{array}$ & Mildly favorable ${ }^{\dagger}$ & $\approx \approx$ & Strongly favorable & Strongly favorable \\
\hline Policy reform facilitates LAI [0/1] & 1 & 1 & 1 & 1 \\
\hline Extraversion of policy making [weak, medium, strong] & Medium & $\approx \approx$ & High & High \\
\hline Development brokering [few/many] ${ }^{\dagger}$ & Few $^{\dagger}$ & $\approx \approx$ & Many & Many \\
\hline Fragmentation of policy-making impacts LAI [0/1] & 1 & 1 & 1 & 1 \\
\hline Civil society mobilization capacity [low/high] ${ }^{\dagger}$ & $\operatorname{High}^{\dagger}$ & $\approx \approx$ & Low & Low \\
\hline NGO financial independence [low/high] & Low & Low & Low & Low \\
\hline $\begin{array}{l}\text { Legal compensation systems with moderate compensation } \\
\text { levels and mixed implementation }[0 / 1]\end{array}$ & 1 & 1 & 1 & 1 \\
\hline Main land property rights system [type] ${ }^{\dagger}$ & Private $^{\dagger}$ & $\approx \approx$ & Leasehold and customary & $\approx \approx$ \\
\hline Investor land tenure security [low, high] & High & $\approx \approx$ & High & High \\
\hline Smallholder land tenure security [low, high $]^{\dagger}$ & High (if private land) ${ }^{\dagger}$ & $\approx \approx$ & Low $^{\dagger}$ & Low $^{\dagger}$ \\
\hline $\begin{array}{l}\text { Accountability of community leaders to land users [weak, } \\
\text { strong] }\end{array}$ & Weak & Weak & Weak & Weak \\
\hline Accountability of governments to land users [weak, strong] ${ }^{\dagger}$ & Strong $^{\dagger}$ & $\approx \approx$ & Weak $^{\dagger}$ & Weak $^{\dagger}$ \\
\hline State authority in land governance [centralized, fragmented] & Fragmented & $\approx \approx$ & Fragmented & $\approx \approx$ \\
\hline $\begin{array}{l}\text { Access of smallholder to state authorities [weak, moderate, } \\
\text { strong] }\end{array}$ & Moderate $^{\dagger}$ & $\approx \approx$ & Weak $^{\dagger}$ & $\approx \approx$ \\
\hline \multicolumn{5}{|l|}{ Social-ecological context } \\
\hline Household employment elsewhere [\%] $^{\dagger}$ & $52(40-65)^{\dagger}$ & - & $28(24-32)^{\dagger}$ & - \\
\hline Yield potential [low, medium, high] & Medium & $\approx \approx$ & High & $\approx \approx$ \\
\hline Actual yields [low, medium, high] & High & $\approx \approx$ & Low & $\approx \approx$ \\
\hline No. of growing days [classes] & $240-269$ & $\approx \approx$ & 180-209 & $\approx \approx$ \\
\hline Smallholder fertilizer use [rare, medium, frequent ${ }^{\dagger}$ & Frequent $^{\dagger}$ & $\approx \approx$ & $\approx \approx$ & Rare \\
\hline Water source for irrigation & $\approx \approx$ & Above ground & $\approx \approx$ & $\approx \approx$ \\
\hline Number of cases following this pattern & 4 & 3 & 2 & 7 \\
\hline
\end{tabular}


were established 16 and 21 years prior to data collection, respectively. Even though land utilization rates (42\% and $59 \%$ of acquired land used) were lower than those observed in the first two patterns, the corresponding LAIs remained, as noted, the main employer in their target region (63\% and 67\%). Only $24 \%$ and $32 \%$ of households sustained their livelihoods via jobs with other employers. However, most of the LAI employees $(83 \%$ and $90 \%$, respectively) earned less than USD \$2/day, with scarcely anyone $(0 \%$ and $3 \%)$ earning over USD \$5/day. Furthermore, many jobs (41\% and $67 \%$ ) were only daily or seasonal, not longterm.

Land tenure in the target areas was previously in the hands of large state farms. However, the de facto prior land use involved smallholders as well. Both the LAI farms were led by international investors with a long-term record of experience in the agricultural system of the targeted region.

The governance system in the two cases exhibited low land tenure security for smallholders and weak government accountability. Civil society mobilization capacity was also low, whereas the dominant agri-food policy discourse was strongly favorable to LAIs as a development strategy.

\section{Pattern 4: Widespread Hostility: Widespread Loss of Land Access, High Conflict Incidence, and Omnipresent Negative Attitudes}

Socio-economic, food security, and environmental impacts Finally, Impact Pattern 4 was exhibited by seven LAIs. Households in the corresponding target regions experienced widespread loss of land access (average 54\%; range of 25-79\%). The reported incidences of conflict between communities and LAIs were high (average $74 \%$; range of $71-95 \%$ for five cases; two outliers at $18 \%$ and $33 \%$ ). The majority of households (average $67 \%$; range of $62-85 \%$ for five cases; two outliers at $20 \%$ and $42 \%$ ) voiced wishes that investors would leave the area. In the Mozambican cases corresponding to Pattern 4, blocked footpaths to key water sources were an additional issue for small-scale land users. Data on food security and employment effects were available for only two of the seven LAIs; the relevant LAIs were more important employers in their area than those in Pattern 1 and Pattern 2 (28\% vs. $15 \%$ and $8 \%$, respectively), with differing impacts on food security. Perceived improvements in infrastructure varied widely $(0-89 \%)$. Residents scarcely perceived any environmental impacts, although the LAIs moderately enhanced risks of acidification, global warming, and energy and water consumption.

\section{Associated features of business models, governance, and land use} changes

The seven farms - six in Mozambique and one in Madagascarfeatured large-scale operational sizes (average 1,900 ha; range $700-6,000$ ha). Aged between 4 and 9 years at the time of research, they produced cereals, oilseeds, cotton, and macadamia. Acquired farm sizes were decidedly large (850-10,000 ha) with varying rates of utilization (15-98\%). However, labor intensities were much smaller $(0.07-0.4 \mathrm{jobs} / \mathrm{ha}$; one outlier at $1.4 \mathrm{jobs} / \mathrm{ha})$ than those in the other patterns. Most of the jobs created (61$90 \%$ ) were daily or seasonal.

Agricultural expansion was present in all seven LAIs of Pattern 4 , fuelling the widespread hostility observed. In all cases, the land targeted for investment was previously used by smallholders. In six of the seven cases, establishment of the LAI triggered indirect land use change by driving smallholders to cut down adjacent forests in order to re-establish their livelihoods.

The governance systems in Pattern 4 consistently displayed strongly pro-LAI national policy discourses. Governance arrangements provided only minimal land tenure security to smallholders. The mobilization capacity of civil society and accountability of governments to land users were weak.

In summary, our results across the four patterns indicate that variation in impact patterns is associated with prior land use, operational farm size, labor intensity and main production type, employment levels, the experience in local agriculture or domestic origin of investors, accountability of government, land tenure security, and civil society capacity. Of less importance are, among other factors, the juridical structure of investments and their main markets. Global governance initiatives do not appear to shape impacts directly.

\section{DISCUSSION: REVISITING CONTROVERSIES OVER LARGE-SCALE AGRICULTURAL INVESTMENTS}

The results offer insights into the social-ecological transformations associated with LAIs. Specifically, this section first discusses why LAIs produce different socio-economic, food security, and environmental impacts. It then discusses the socialecological transformations related to land use systems and the role of business models and governance changes, before reflecting on implications of LAIs for resilience and social-ecological transformations at regional scales.

Why do Large-scale Agricultural Investments Produce Different Socio-economic, Food Security, and Environmental Impacts?

Why do socio-economic impacts vary?

First, the LAIs in our sample displaced smallholders from grazing areas or farmland to much different extents. In nine of the 16 cases, LAI farms displaced between $5 \%$ and $79 \%$ of current neighboring households from grazing areas or farmland. In seven cases, survey and interview respondents perceived no LAI-related losses of land access. This variation is consistently associated with prior land use, farm size, and national/local governance systems. The LAIs that avoided displacing smallholders all targeted land that was previously used for large-scale farming. ${ }^{3}$ Their operational farm sizes were moderate (23-256 ha). In contrast, the LAIs that displaced smallholders featured much larger operational farm sizes (830-6,000 ha) and consistently targeted land previously used by small-scale farmers. In contrast, in the LAIs without smallholder displacement in Pattern 1, investors accessed land previously used by agribusinesses. Stronger government accountability and mobilization capacity of civil society may have contributed to safeguard land access and tenure security among smallholders. These governance features were lacking among the LAIs exhibiting displacement (Patterns 3 and 4).

Second, the labor impacts of LAIs and the dependency of a region on particular farms are not solely a function of the number of jobs created, but also of the local availability of alternative livelihood options. The LAIs comprising Pattern 1 were just one among several livelihood options in Kenya's Nanyuki area. In 
contrast, the two Mozambican LAIs comprising Pattern 3 were the main employer in their region. The dependency of a region on one main employer (quasi-monopsony) is associated with lower wages and more short-term employment. Pattern 2 LAIs created 1,162 jobs on average, similar to the average of 1,101 jobs created by Pattern 3 LAIs. However, only $8 \%$ of Pattern 2 households worked for LAIs, compared with $65 \%$ of Pattern 3 households.

Third, all the LAIs in our sample caused conflicts and all but one triggered negative local attitudes toward investors - but again to varying degrees. Hostility rates were highest in Pattern 4 LAIs, smallest in Pattern 2, and moderate in Pattern 1. Agricultural expansion, loss of land access, and environmental impacts may explain these differences. In Pattern 4, agricultural expansion-i.e., the replacement of natural vegetation with cropland - and loss of land access appear to have contributed to conflict incidence and negative local attitudes. Agricultural expansion was also present in three of four Pattern 1 cases, but did not displace smallholders. Instead, conflicts in Pattern 1 were related to impacts on local environmental quality due to water over-extraction, air pollution, chemical exposure, and pest increases. Agricultural expansion, loss of land access, and impacts on local environmental quality are much lower in the low-conflict LAIs of Pattern 2.

\section{Why do food security impacts vary?}

Our findings suggest that LAIs influence household food security in two key ways: by creating livelihood options for engaged households (i.e., employed households or contract farmers) and by causing loss of land access. In other words, the results confirm that livelihood options and land access mediate the effects of LAIs on food security.

Pattern 1 and Pattern 2 LAIs were associated with slightly better food security - in terms of food consumption, household dietary diversity, assets, food provision-among engaged households, compared with non-engaged households in the target regions or households in counterfactual areas. Notably, in both patterns, smallholders did not lose land access to the LAIs and LAIrelated employment or contract farming was just one of several livelihood options available.

However, in Pattern 1, the food security impacts are spreading in terms of women's dietary diversity and coping strategies, i.e., engaged households are more frequently identified both as most food secure as well as most food insecure along these two indicators. Counterfactual households applied fewer coping strategies than non-engaged households, especially immediately after the production season. However, food security levels might have appeared worse had interviews been conducted a few months earlier, prior to harvest. Our findings also suggest that female-headed households are disadvantaged in terms of access to employment and contracting opportunities, with implications for food security and dietary quality — especially in Madagascar.

Why do environmental impacts vary?

The on-site environmental impacts were highest among Pattern 1 LAIs. These LAIs consistently involved processes of agricultural intensification, such as implementation of monocultures, irrigation, and agrochemical use, and high levels of mechanization. The same was also true of LAIs of other patterns that exhibited high environmental impacts. Thus, we find evidence of a consistent association between agricultural intensification and on-site environmental degradation.

At the foot of the natural water tower of Mt. Kenya, Nanyuki's climatic and topographical features offer key ecological preconditions for intensive LAI horticultural production. Horticultural farms require more irrigation and have greater environmental impacts than the generally less intensive (at least in terms of irrigation) production models studied in Mozambique and Madagascar.

The input intensity and irrigation needs of different production models also shape off-site environmental impacts. For instance, households in Kenya perceived the input-intensive Pattern 1 LAIs as over-extracting river water and polluting the air and water with chemicals. This has led farmers living downstream to change their land management practices, e.g., abandoning irrigated crops and switching to crops they perceived to be more resistant to the lower water quality (Zaehringer et al. 2018b). In contrast, the Pattern 2 LAI in in Madagascar - one featuring a contract farming system and the other a Jatropha plantation that failed shortly before interviews were conducted-required few external inputs, and irrigation was unnecessary. This eliminated household concerns about negative impacts on land or water resources.

Impact variations can also be explained by management interventions explicitly adopted to reduce environmental harms, sometimes compromising short-term profitability. Typical conservation measures include preservation of environmentally significant tree species, creation of riparian buffer zones, preservation of high conservation value areas, avoidance of cultivation on steep terrain and/or fragile soils, and integrated pest management. In some cases, low productivity soils were made more productive by LAIs using agronomic technologies and inputs that were inaccessible or unaffordable to small-scale farmers. In the cases in Mozambique and Madagascar, we observed more moderate agrochemical use, possibly as a result of lack of infrastructure or cost concerns rather than an explicit desire to limit environmental harms.

\section{Agricultural Investment, Resource Frontiers, and the Transformation of Land Systems}

Our results show that 12 of the 16 LAIs in our sample caused expansion of agricultural resource frontiers. This share is larger than the range of $32-60 \%$ identified in previous global analyses (Messerli et al. 2014, Nolte et al. 2016). These LAIs mobilized capital investments and expanded agricultural areas at the expense of forest cover, grasslands, and shrublands at the perimeters of LAI farms (Eckert et al. 2018, Zaehringer et al. 2018a, b). Data on land use change were lacking for three LAIs. Interestingly, only one LAI did not involve agricultural expansion. In this Kenyan case, greenhouses for flower production replaced vegetable production on intensively cultivated, irrigated cropland. In the $5 \mathrm{~km}$ surroundings of this LAI, a sizable amount of previously rainfed cropland ( $883 \mathrm{ha}$ ) was left fallow, and together with some shrubland (109 ha) had become (temporary) grassland $(920 \mathrm{ha})$. Also, several forest plantations had been established nearby, giving rise to increased overall forest area (374 ha).

Large-scale agricultural investments drive agricultural intensification. In 12 of the 16 LAIs, remote sensing and fieldwork data indicated land use conversions from small-scale farming to irrigated 
cropland or greenhouses at the perimeter of LAI farms. Among the four cases lacking intensification, one LAI involved an investment implemented on grassland (thus expanding agricultural area, but not intensifying previous agriculture); data were lacking for two LAIs; and one case was the failed investment in Madagascar, in which land cover was converted from grassland to jatropha and back again.

Indirect land use changes were observed in 13 of the 16 LAIs. Six LAIs involved construction of small-scale fields by clearing adjacent forests for agriculture. In seven other cases, the LAIs induced land management change on small-scale farms. However, these spillovers did not occur primarily via knowledge transfer, as was expected based on previous research (cf. "Current Controversies around Large-scale Agricultural Investments" above). In Kenya, small-scale farmers abandoned irrigated crops in response to perceived over-extraction and pollution of water by LAIs. In one Malagasy case, cropland management changed because land users lacked sufficient labor to farm their own land separately while working for LAI farms. In the two remaining cases in Madagascar, household members lost jobs at the LAI farm and thus changed management on their own cropland, e.g., planting new crops for sale $(n=2)$ or learning new techniques from the LAI $(n=1)$.

In terms of off-site land use changes, Pattern 1 and Pattern 2 LAIs generally involved loss of natural habitats - except in the vicinity of one LAI where several tree plantations were implemented. In Pattern 1 LAIs, primarily bush-, shrub- and grasslands were converted to small-scale cropland. In Pattern 4 LAIs in Mozambique, primarily forest and natural wetlands were converted to small-scale cropland. The Pattern 4 LAIs in Madagascar did not cause major off-site land use/land cover changes in the vicinity of investment areas, but did cause major on-site conversion (grassland to LAI cropland). No or only minimal, temporary land use/land cover changes were observed for Pattern 2 LAIs, mostly because they relied on a contractfarming scheme that did not cause land use changes or because of investment failure making land use change strictly temporary.

\section{The Role of Business Models}

Our results indicate that specific business-model features are associated with particular impacts. We have assessed 21 indicators of business model features here (Append. 1). Among those, we find that labor intensity, prior land use, utilization of land, farm size, type of production, and experience in local agricultural systems are of particular importance, because they are associated consistently with particular impacts.

First, the LAIs in our sample varied widely in terms of labor intensity. Some LAIs created as many as 20 jobs/ha, whereas others realized no more than 0.07 jobs/ha. Large-scale agricultural investments with higher labor intensity tended to operate on smaller farms, thereby limiting smallholder displacement effects. This, in turn, tends to be associated with slightly better local food security by limiting land access losses and boosting employment effects. However, the LAIs in our sample with higher labor intensity operated with high levels of input intensity and mechanization, thereby inducing adverse local and global environmental impacts. The LAIs exhibiting low labor intensity operated over very large land areas, ranging between 830 ha and 6,000 ha, thus compromising land access among smallholders. In terms of wages, even LAIs with high labor intensity rarely paid salaries higher than USD \$5/day, despite exporting produce to high-income countries.

Second, LAI production models influenced labor intensity, and were influenced by standardization processes. Production of fresh goods for international markets is associated with highly specialized, industrialized production and high labor intensitycharacteristics absent from other business models. The flower and vegetable farms in Kenya exhibited these features. The flower farms displayed the highest labor intensity, whereas the vegetable farms were more varied in labor intensity based on different vegetables demanding different levels of mechanization. Production models in the horticultural cluster in Kenya did not vary according to the age of the farms or the experience in agriculture or origin of investors; however, standardization and competition in the sector have forced all the producers to adopt the same production model over time, including similar technologies of drip irrigation, water ponds, and greenhouses. Along the way, contract farming has diminished due to the increased difficulty of meeting strict standards imposed by international value chains.

Third, our results suggest that investor experience in local agricultural systems can improve the performance of LAIs in certain areas. More locally knowledgeable, networked investors may gain land access in less intrusive ways (Burnod et al. 2013) and may be familiar with the specific agronomic conditions of targeted areas. Indeed, the Pattern 4 LAIs ("widespread hostility") in our sample consistently involved international investors as opposed to domestic investors or managers. However, experience in local agricultural systems was not a sufficient condition to eliminate unsustainable impacts: four of seven investors of Pattern 4 LAIs were familiar with local conditions, yet their investments still generated widespread hostility. Finally, economically successful implementation of LAIs in the Nanyuki area was associated with local investors, commercial farmers, or investors with experience in the sector who were able to recruit experienced managers for the type of production needed.

\section{Governance of Agricultural Investments}

Our cross-country analysis also sheds light on how agricultural and land policy development differentially shape LAI implementation and impacts. Our focus here is on actual implementation of legal and policy provisions, not merely their existence on paper. In this way, despite the progressive land tenure rights for communities recognized in Mozambican or Malagasy law for instance, we observed that those rights were seldom enforced on the ground.

In Kenya's Nanyuki area, land tenure for smallholders is relatively secure, and the legal status of their land appeared to shield them from land acquisitions against their will. Investors were accessing land already used by agribusinesses rather than smallholders. Government accountability toward smallholders and civil society mobilization capacity were comparatively high, aiding protection of legal land rights among small landowners. Importantly, this tenure security also safeguards the interests of investors, providing them security for long-term investments, which is economically necessary for the type of horticulture production found in this area. This relatively secure land tenure and mode of accessing land by investors shapes impact patterns, as 
displacements are essentially ruled out (Pattern 1 and Pattern 2). The relative inability of LAIs to obtain large areas of land favors highly capitalized, labor-intensive investments with high rates of utilization. Nevertheless, land and water use conflicts remain, as seen when pastoralists use the land of large privately owned ranches during droughts (Jacobi et al. 2018, Ngutu et al. 2018) or when water over-extraction by upstream users-large and small landowners - depletes river flows in downstream areas. Local governance somewhat mitigates these tensions, as in the case of water user associations that help regulate water use and resolve conflicts (Baldwin et al. 2016, McCord et al. 2017, Ngutu et al. 2018).

When compared with Madagascar and Mozambique, Kenya appears to exhibit lower levels of policy extraversion (i.e., influence of external actors in shaping public policies) in domestic agricultural and land policy. However, Kenyan LAIs willingly incorporate voluntary sustainability standards based on their high degree of foreign market focus. Most of Kenya's horticultural farms are certified according to one or more voluntary sustainability standards - such as GlobalGAP, the Kenyan Flower Council, or Fairtrade - which are often viewed as necessary for farms to market their flowers or vegetables abroad.

In Madagascar, LAIs have gained a central place in land and agricultural policy in the last decade. Official discourses - such as that of the 2015 Agriculture, Livestock, and Fisheries Sector Programme (PSAEP) - have actively promoted the idea of moving from "peasant" agriculture to market-oriented agriculture, fostering agricultural growth by means of large-scale production. One of PSAEP's flagship goals was to develop two million hectares of agricultural investment areas. This was planned for implementation via Agricultural Investment Zones (ZIA) offering secure access to arable land to large-scale investors. Promulgation of the ZIA instrument in 2016 triggered counter mobilization on the ground, reinforced by national and foreign NGOs. Based on this, policymakers adapted the initial concept, expanding it to offer secure land access to small-scale farmers as well. Following a tense pre-electoral period, they eventually scrapped the ZIA project. This process points to policymakers first incorporating critiques, suspending corresponding policy processes, and ultimately maintaining the status quo. This situation has wider implications for implementation of LAIs in Madagascar. Despite initiatives to promote LAIs across the country, more than $90 \%$ of announced deals have not been implemented (Burnod and Andriamanalina 2017). The land reform, legally protecting local rights on agricultural land, has not affected investors' land access networks of actors. Investors' land demand has created incentives for the land administration to not promote the land reform but to move backward by claiming all the land as state-owned land, by strengthening the centralization of land management, and by seizing opportunities of corruption (Burnod and Andriamanalina 2017). Lack of enforcement of local land rights engenders conflict or fears of conflict and stalls start-up phases, scaring away commercial investors. The LAIs implemented in Madagascar to date are exceptions, promoted by investors who managed to navigate the difficult context (Burnod and Andriamanalina 2017).

Similarly, in Mozambique, official policy discourses and the country's commitment to the New Alliance for Food Security and
Nutrition (NAFSN) in 2012 have created, on paper, a favorable political climate for LAIs. However, the actual political climate for LAIs has been less open for LAIs after some of them were associated with scandals and were forced to be abandoned based on advocacy and resistance by international and local NGOs linked to foreign civil society movements (Di Matteo and Schoneveld 2016). Despite recurring efforts, global-level rhetoric, and initiatives - especially emphasizing Mozambique's land law - did not yet influence national governance of LAIs in Mozambique. Much of the responsibility and agency regarding implementation of LAIs lies with national political elites. They may negotiate deals with investors but are wary of antagonizing a vivid and connected civil society that might denounce the deals. Hence, the implementation of LAIs in Mozambique may depend more on the number of political intermediaries and brokers negotiating deals than on the official political discourses around LAIs. High numbers of intermediaries have deterred investors for years. Lack of formalization of land use rights exacerbates challenges. Land rights are often not formally registered, not demarcated, and not surveyed. This might have been perceived by investors as a great appeal at first, but it soon led to contestation and conflicts with rural communities because the land was indeed not idle but used. The situation led to a deadlock in several cases, which did not help the investors in the long run. After a while, representatives of investors and donor communities were willing to get greater clarity around land rights. Major donors in Mozambique have dedicated programs to modify the land administration system for more than 10 years. Therefore, if land rights were to be enforced, LAIs may be more restricted on the one hand. On the other, the law does not only protect communities' rights, it also provides for opportunities for LAIs, which are encouraged providing communities get compensated (Bourblanc and Belenfant 2018, Salomão 2020).

\section{Implications of Large-scale Agricultural Investments for Resilence and Social-Ecological Transformations at Regional Scales}

Large-scale agricultural investments transform the socialecological systems in which they operate, with profound implications for the resilience of livelihoods and land systems (Schoneveld et al. 2011, Magliocca et al. 2019). The four patterns identified here offer nuances to the notion of resilience grabbing, i.e., the process by which LAIs reduce the resilience of local communities as a consequence of displacing them from access to food and non-food resources held as commons (Haller et al. 2020). This process may operate most concretely in LAIs of Patterns 3 and 4 with large losses of land access among communities. In contrast, the LAIs in Patterns 1 and 2 do not deprive smallholders and communities from access to land and related commons. In these patterns, families tend to use labor opportunities on LAI farms when they are in need of monetary income amidst alternative livelihood options (Reys et al., unpublished manuscript). This is also reflected in slightly better food security outcomes for the engaged households in Patterns 1 and 2. These opportunities may therefore contribute to resilience (Lade et al. 2020). However, this may only hold for privileged households with enough household labor and land, whereas the more vulnerable households lost in food-related coping capacities, and women's dietary diversity was lower among engaged households in Pattern 1. An increased wage dependency also increases vulnerability to the risk of failure of LAIs (Nolte 2020), and the conflicts about 
environmental impacts of air and water pollution as well as pest increases may indicate an alternative mechanism of adverse impacts of LAIs on resilience, which is consistent with findings for LAIs in Sierra Leone (Bottazzi et al. 2018) and Lao PDR (Nanhthavong et al. 2021).

This study offers insights into how LAIs represent drivers of social-ecological transformations at regional scales (Rocha et al. 2019), with differences observed in our three focal countries. Laikipia County in Kenya and - to a limited extent - the study area in the Nacala Corridor in Mozambique experienced cluster effects in the region's economic structure (Porter 2000, Ketels and Memedovic 2008), as they saw the inflow of LAIs in similar hortiand agricultural sectors. In Kenya, a cluster of highly specialized horticultural projects enabled the development of specialized human competences (technical, managerial) and support services (Giger et al. 2020), a development that can provide comparative advantage for neighboring LAI farms (Porter 2000). This can be interpreted as a profound change in the regional economic structure, transforming with it important components of the social-ecological system toward highly intensive land uses. The pre-existing large-scale farms, which were devoted to mechanized farming or extensive ranching, have been transformed into labor intensive production units, using high numbers of laborers, and changing their livelihood strategies away from small-scale, subsistence-oriented maize farming. In our study area in Mozambique, many of the new investments have failed (Di Matteo and Schoneveld 2016, Glover and Jones 2019; J. L. Adalima, unpublished manuscript), but we still find many LAIs that focus on commercial crops (such as sisal, tea, macadamia, maize or soya) (J. L. Adalima, unpublished manuscript). In contrast, the LAIs in Madagascar displayed a much more patchy pattern of single, often larger LAIs (Burnod and Andriamanalina 2017), geographically disbursed across the country, with no priority region or investment corridor discernible. A lengthy land concession process and conflicts due to frequent overlaps with communal land use have left few investments active (Burnod et al. 2013). Nevertheless, whether the LAIs are active or not, they have transformed the land tenure regime, by reversing the land tenure reform policy (Burnod and Andriamanalina 2017), weakening the opportunities for a progressive land tenure systems reform.

Therefore, the considered LAIs in Kenya and Mozambique seem to contribute to social-ecological transformation pathways of agro-industrialization at a regional scale. Where the LAIs are economically viable, they contribute to shift entire regional production systems from reliance on local markets and subsistence to national and international markets. However, new dependencies and risks arise, which can reduce resilience of livelihoods. Moreover, the ecological changes in such socialecological transformations are clearly far reaching: intensive use of external inputs, often intensive water use, and dependency on intercontinental air transport, causing carbon emissions, represent a transformation in the ecological sphere. These changes are strongest in LAIs of Pattern 1 with its focus fresh products for global markets, and they are moderately strong in Patterns 2 and 4 , as these LAIs mostly produce soy and cereals for domestic markets, using moderate levels of inputs.

\section{CONCLUSIONS}

The present study demonstrates how differences in business models, governance systems, and land use changes mediate the influence of global drivers of change in land use and agro-food systems, influencing how LAIs impact development in Kenya, Madagascar, and Mozambique. Our results demonstrate that LAI impacts do not neatly fit one unifying land-grab narrative. Instead, we find that the 16 LAIs in our sample follow four distinct impact patterns: conflicted neighborhood, moderate neighborhood, land loss to main employer, and widespread hostility. Each pattern features a distinct profile of socio-economic, food security, and environmental impacts. The results further demonstrate how particular features of business models, governance systems, and land use changes influence the socio-economic, food security, and environmental impacts of LAIs.

There is no single business model that generates consistent impact patterns. Instead, labor intensity, prior land use, utilization of land, farm size, type of production, and experience in local agricultural systems are the key features of business models shaping LAI impacts. Impacts further depend on how public policies provide for land tenure security, accountability of state and local elites toward land users, and the mobilization capacity of civil society. Finally, LAIs generate socio-economic, food security, and environmental impacts by expanding agricultural resource frontiers, agricultural intensification, and indirect land use changes.

Most evident is the key trade-off between losses in access to land for previous land users, losses in environmental quality, and the emergence of new wage-dependent livelihoods. When labor intensities are low, this trade-off is particularly likely to trigger conflicts. Preferential inclusion of particular community members or attraction of migrants for employment in the region can intensify conflicts (Bottazzi et al. 2016). Effective measures to minimize this trade-off include strong provisions for smallholder land tenure security, strong civil society, government recognition for smallholder rights, and targeting of LAIs toward land already under large-scale production rather than displacing small-scale farmers.

Large-scale agricultural investments and rural development questions in the regions of this study - but also elsewhere in Africa (Collier and Dercon 2014) — should not be framed as a dichotomous choice between promotion of commercial agriculture vs. smallholder agriculture. The key challenge is to identify what organizational strategies, governance structures, and agro-ecological practices are most suited to develop inclusive, resilient, and diversified rural economies that foster growing incomes, improved food security, and rapid reductions in poverty, while operating within environmental limits. System dynamics modeling is a methodology for promising future research to tackle this challenge. Our results indicate that commercial agriculture and increased rural wage labor can be components of such strategies under certain conditions, but that they will fail without substantial, sustained increases in the agro-ecological productivity, economic viability, and inclusiveness of smallholder agriculture, land tenure security, agro-ecological land management, and support for broader patterns of endogenous agrarian transformation. 
Responses to this article can be read online at: https://www.ecologyandsociety.org/issues/responses. php/12653

\section{Acknowledgments:}

This research was funded jointly by the Agence Nationale de la Recherche, France; National Research Foundation, South Africa; and Swiss National Science Foundation, Switzerland, via the Belmont Forum and Joint Programming Initiative on Agriculture, Food Security and Climate Change (FACCE-JPI) (Grant Number: 40FA40_160405). The Land Matrix Initiative provided support in data and data analysis. We are grateful to Anu Lannen for language editing. This article contributes to the Global Land Programme (glp.earth).

\section{Data Availability:}

The datalcode that support the findings of this study are uploaded as part of this submission.

\section{LITERATURE CITED}

Adams, T., J. D. Gerber, M. Amacker, and T. Haller. 2018. Who gains from contract farming? Dependencies, power relations, and institutional change. The Journal of Peasant Studies 46 (7):1435-1457. https://doi.org/10.1080/03066150.2018.1534100

Ahrends, A., P. M. Hollingsworth, A. D. Ziegler, J. M. Fox, H. Chen, Y. Su, and J. Xu. 2015. Current trends of rubber plantation expansion may threaten biodiversity and livelihoods. Global Environmental Change 34:48-58. https://doi.org/10.1016/j. gloenvcha.2015.06.002

Alden Wily, L. 2012. Looking back to see forward: the legal niceties of land theft in land rushes. The Journal of Peasant Studies 39(3):751-775. https://doi.org/10.1080/03066150.2012.674033

Ali, D. A., K. Deininger, and A. Harris. 2017. Using national statistics to increase transparency of large land acquisition: evidence from Ethiopia. World Development 93:2-74. https://doi. org/10.1016/j.worlddev.2016.12.027

Allaverdian, C., editor. 2010. Agricultures familiales et sociétés civiles face aux investissements dans les terres dans les pays du Sud. Coordination Sud, Paris, France.

Anseeuw, W., M. Boche, T. Breu, M. Giger, J. Lay, and P. Messerli. 2012. Transnational land deals for agriculture in the global south. Analytical report based on the land matrix database. Centre for Development and Environment (CDE), Bern, Switzerland / Centre de coopération internationale en recherche agronomique pour le développement (CIRAD), Montpellier, France / German Institute for Global and Area Studies (GIGA), Hamburg, Germany.

Anseeuw, W., J. Lay, P. Messerli, M. Giger, and M. Taylor. 2013. Creating a public tool to assess and promote transparency in global land deals: the experience of the Land Matrix. The Journal of Peasant Studies 40(3):521-530. https://doi.org/10.1080/03066150.2013.803071

Antonelli M., G. Siciliano, M. E. Turvani, and M. C. Rulli. 2015. Global investments in agricultural land and the role of the EU: drivers, scope and potential impacts. Land Use Policy 47:98-111. https://doi.org/10.1016/j.landusepol.2015.04.007

Baldwin, E., C. Washington-Ottombre, J. Dell'Angelo, D. Cole, and T. Evans. 2016. Polycentric governance and irrigation reform in Kenya. Governance 29(2):207-225. https://doi.org/10.1111/ gove. 12160

Barbier, E. B. 2020. Long run agricultural land expansion, booms and busts. Land Use Policy 93:103808. https://doi.org/10.1016/j. landusepol.2019.01.011

Bergtold, J. S., M. M. Caldas, A. C. Sant'anna, G. Granco, and V. Rickenbrode. 2017. Indirect land use change from ethanol production: the case of sugarcane expansion at the farm level on the Brazilian Cerrado. Journal of Land Use Science 12 (6):442-456. https://doi.org/10.1080/1747423X.2017.1354937

Boche, M., and W. Anseeuw. 2014. Unraveling "land grabbing": different models of large-scale land acquisition in Southern Africa. Land Deal Politics Initiative (LDPI) Working paper no. 46, LDPI, International Institute of Social Studies, The Hague, The Netherlands.

Boillat, S., and P. Bottazzi, P. 2020. Agroecology as a pathway to resilience justice: peasant movements and collective action in the Niayes coastal region of Senegal. International Journal of Sustainable Development and World Ecology 27(7):662-677. https://doi.org/10.1080/13504509.2020.1758972

Borras, S. M. Jr., R. Hall, I. Scoones, B. White, and W. Wolford. 2011. Towards a better understanding of global land grabbing: an editorial introduction. Journal of Peasant Studies 38 (2):209-216. https://doi.org/10.1080/03066150.2011.559005

Borras, S. M. Jr., and J. C. Franco. 2012. Global land grabbing and trajectories of agrarian change: a preliminary analysis. Journal of Agrarian Change 12(1):34-59. https://doi.org/10.1111/ j.1471-0366.2011.00339.x

Bottazzi, P., A. Goguen, and S. Rist. 2016. Conflicts of customary land tenure in rural Africa: is large-scale land acquisition a driver of 'institutional innovation'? The Journal of Peasant Studies 43 (5):971-988. https://doi.org/10.1080/03066150.2015.1119119

Bottazzi, P., D. Crespo, L. O. Bangura, and S. Rist. 2018. Evaluating the livelihood impacts of a large-scale agricultural investment: lessons from the case of a biofuel production company in northern Sierra Leone. Land Use Policy 73:128-137. https://doi.org/10.1016/j.landusepol.2017.12.016

Breu, T., C. Bader, P. Messerli, A. Heinimann, S. Rist, and S. Eckert. 2016. Large-scale land acquisition and its effects on the water balance in investor and host countries. PLOS One 11(3): e0150901. https://doi.org/10.1371/journal.pone.0150901

Bürgi, E. 2015. Sustainable investment in land in the global South: What would it require from a coherence perspective? The case of Sierra Leone. Questions of International Law 21:17-37. 
Burnod, P., and B. S. Andriamanalina. 2017. Réforme foncière et accueil des investisseurs à Madagascar : l'ambivalence de la politique foncière. Revue. Géographie Economie Société 19:357-376.

Burnod, P., M. Gingembre, and R. Andrianirina Ratsialonana. 2013. Competition over authority and access: international land deals in Madagascar. Development and Change 44(2):357-379. https://doi.org/10.1002/9781118688229.ch8

Burnod, P., A. Reys, W. Anseeuw, M. Giger, S. Mercandalli, B. Kiteme, and T. Ralandison. 2018. Labor impacts of large agricultural investments: focus on Mozambique, Kenya and Madagascar. In Annual Work Bank Conference on Land and Poverty, 20-24 March 2018, Washington, D.C., USA.

Camisón, C., and A. Villar-López. 2010. Business models in Spanish industry: a taxonomy-based efficacy analysis. Manage 13(4):298-317.

Ceddia, M. G. 2019. The impact of income, land and wealth inequality on agricultural expansion in Latin America. Proceedings of the National Academy of Sciences of the United States of America 116(7):2527-2532. https://doi.org/10.1073/ pnas. 1814894116

Ceddia, M. G., N. O. Bardsley, S. Gomez-y-Paloma, and S. Sedlacek. 2014. Governance, agricultural intensification, and land sparing in tropical South America. Proceedings of the National Academy of Sciences of the United States of America 111(20):7242-7247. https://doi.org/10.1073/pnas.1317967111

Chamberlain, W. O., and W. Anseeuw, editors. 2017. Inclusive businesses in agriculture. Sun Press, Stellenbosch, South Africa. https://doi.org/10.18820/9781928355090

Chamberlain, W. O., and W. Anseeuw. 2018. Inclusive businesses and land reform: corporatization or transformation? Land 7 (1):18. https://doi.org/10.3390/land7010018

Collier, P., and S. Dercon. 2014. African agriculture in 50 years: smallholders in a rapidly changing world? World Development 63:92-101. https://doi.org/10.1016/j.worlddev.2013.10.001

Cotula, L. 2009. Land grab or development opportunity? Agricultural investment and international land deals in Africa. International Institute for Environment and Development, London, UK.

Cotula, L. 2011. Land deals in Africa: what is in the contracts? International Institute for Environment and Development, London, UK.

Cotula, L. 2012. The international political economy of the global land rush: a critical appraisal of trends, scale, geography and drivers. The Journal of Peasant Studies 39(3-4):649-680. https:// doi.org/10.1080/03066150.2012.674940

Cotula, L., C. Oya, E. A. Codjoe, A. Eid, M. Kakraba-Ampeh, J. Keeley, and R. O. Asare. 2014. Testing claims about large land deals in Africa: Findings from a multi-country study. The Journal of Development Studies 50(7):903-925. https://doi. org/10.1080/00220388.2014.901501

Cramb, R. A. 2013. Palmed off: incentive problems with jointventure schemes for oil palm development on customary land.
World Development 43:84-99. https://doi.org/10.1016/j. worlddev.2012.10.015

da Silva, M. 2018. Potential on- and off-site environmental impacts of large agricultural investments versus small-scale farming in Kenya and Mozambique. Thesis, Department of Plant and Soil Sciences, University of Pretoria, South Africa.

Davis K. F., K. Yu, M. C. Rulli, L. Pichdara, and P. D'Odorico. 2015. Accelerated deforestation driven by large-scale land acquisitions in Cambodia. Nature Geoscience 8(10): 772.

Deininger, K., and D. Byerlee, 2012. The rise of large farms in land abundant countries: do they have a future? World Development 40:701-714.

Deininger, K., and F. Xia. 2016. Quantifying spillover effects from large land-based investment: the case of Mozambique. World Development 87:227-241. https://doi.org/10.1016/j.worlddev.2016.06.016

Deininger, K., and F. Xia. 2018. Assessing the long-term performance of large-scale land transfers: challenges and opportunities in Malawi's estate sector. World Development 104:281-296. https://doi.org/10.1016/j.worlddev.2017.11.025

Delaney, A., T. Evans, J. McGreevy, J. Blekking, T. Schlachter, K. Korhonen-Kurki, P. A. Tamas, C. A. Crane, H. Eakin, W. Förch, L. Jones, D. R. Nelson, C. Oberlack, M. Purdon, and S. Rist. 2018. Governance of food systems across scales in times of socialecological change: a review of indicators. Food Security 10 (2):287-310. https://doi.org/10.1007/s12571-018-0770-y

Dell'Angelo, J., P. D’Odorico, and M. C. Rulli. 2017a. Threats to sustainable development posed by land and water grabbing. Current Opinion in Environmental Sustainability 26: 120-128.

Dell'Angelo, J., P. D’Odorico, M. C. Rulli, and P. Marchand. 2017b. The tragedy of the grabbed commons: coercion and dispossession in the global land rush. World Development 92:1-12.

Dell'Angelo, J., M. C. Rulli, and P. D'Odorico. 2018. The global water grabbing syndrome. Ecological Economics 143:276-285. https://doi.org/10.1016/j.ecolecon.2017.06.033

De Schutter, O. 2011. How not to think of land-grabbing: three critiques of large-scale investments in farmland. The Journal of Development Studies 38(2):249-279. https://doi.org/10.1080/03$\underline{066150.2011 .559008}$

Di Matteo, F., and G. C. Schoneveld. 2016. Agricultural investments in Mozambique: an analysis of investment trends, business models and social and environmental conduct. Working Paper 201. Centre for International Forestry Research (CIFOR), Bogor, Indonesia. https://doi.org/10.17528/cifor/005958

D’Odorico, P., M. C. Rulli, J. Dell'Angelo, and K. F. Davis. 2017. New frontiers of land and water commodification: socioenvironmental controversies of large-scale land acquisitions. Land Degradation and Development 28(7):2234-2244. https:// doi.org/10.1002/1dr.2750

Eckert, S., B. Kiteme, E. Njuguna, and J. G. Zaehringer. 2018. Agricultural expansion and intensification in the foothills of Mount Kenya: a landscape perspective. Remote Sensing 9(8):784. https://doi.org/10.3390/rs9080784 
Eisenack, K., S. Villamayor-Tomas, G. Epstein, C. Kimmich, N. Magliocca, D. Manuel-Navarrete, C. Oberlack, M. Roggero, and D. Sietz. 2019. Design and quality criteria for archetype analysis. Ecology and Society 24(3): 6. https://doi.org/10.5751/ ES-10855-240306

Fairbairn, M. 2013. Indirect dispossession: domestic power imbalances and foreign access to land in Mozambique. Development and Change 44(2):335-356. https://doi. org/10.1002/9781118688229.ch7

Fitawek, W., S. L. Hendriks, F. Fossi, and A. Reys. 2019. The impact of large-scale agricultural investments on household food security in two areas of Madagascar. Paper presented at the African Agricultural Economics Association's Sixth International Conference, 23-26 September 2019, Abuja, Nigeria. [online] URL: https://ideas.repec.org/p/ags/aaae19/295895.html

Fouilleux, E., N. Bricas, and A. Alpha. 2017. 'Feeding 9 billion people': global food security debates and the productionist trap. Journal of European Public Policy 24(11):1658-1677. https://doi. org/10.1080/13501763.2017.1334084

Ganter, B., and R. Wille. 2012. Formal concept analysis: mathematical foundations. Springer Science and Business Media, New York, New York, USA.

Gerber, J. D., and J. F. Gerber. 2017. Decommodification as a foundation for ecological economics. Ecological Economics 131:551-556. https://doi.org/10.1016/j.ecolecon.2016.08.030

German, L., G. Schoneveld, and E. Mwangi. 2013. Contemporary processes of large-scale land acquisition in SubSaharan Africa: legal deficiency or elite capture of the rule of law? World Development 48:1-18. https://doi.org/10.1016/j. worlddev.2013.03.006

German, L., G. Schoneveld, and P. Pacheco. 2011. The social and environmental impacts of biofuel feedstock cultivation: evidence from multi-site research in the forest frontier. Ecology and Society 16(3): 24. https://doi.org/10.5751/ES-04309-160324

German, L., E. Cavane, A. Sitoe, and C. Braga. 2016. Private investment as an engine of rural development: a confrontation of theory and practice for the case of Mozambique. Land Use Policy 52:1-14. https://doi.org/10.1016/j.landusepol.2015.11.012

Giger, M., W. Anseeuw, S. L. Hendriks, M. van der Laan, J. Annandale, M. Bourblanc, E. Fouilleux, S. Mercandalli, P. Burnod, A. Reys, S. Eckert, B. Kiteme, C. Oberlack, J. G. Zaehringer, C. Adelle, and P. Messerli. 2018. Impacts of large agricultural investments - a comparative analysis from three African countries. Land and Poverty Conference 2018: Land Governance in an Interconnected World, 19-23 March 2018, Washington, D.C., USA.

Giger, M., E. Mutea, S. Eckert, B. Kiteme, W. Anseeuw, and J. G. Zähringer. 2020. Large agricultural Kenya's Nanyuki area: inventory and analysis of business models. Land Use Policy 99: 104833. https://doi.org/10.1016/j.landusepol.2020.104833

Glover, S., and S. Jones. 2019. Can commercial farming promote rural dynamism in sub-Saharan Africa? Evidence from Mozambique. World Development 114:110-121. https://doi. org/10.1016/j.worlddev.2018.09.029
Hajjar, R., A. N. Ayana, R. Rutt, O. Hinde, C. Liao, S. Keene, S. Bandiaky-Badji, and A. Agrawal. 2019. Capital, labor, and gender: the consequences of large-scale land transactions on household labor allocation. The Journal of Peasant Studies 47 (3):566-588. https://doi.org/10.1080/03066150.2019.1602520

Hakizimana, C., P. Goldsmith, A. A. Nunow, A. W. Roba, and J. K. Biashara. 2017. Land and agricultural commercialisation in Meru County, Kenya: evidence from three models. The Journal of Peasant Studies 44(3):555-573. https://doi.org/10.1080/03066$\underline{150.2016 .1260555}$

Hall, R., I. Scoones, and D. Tsikata. 2015a. Africa's land rush: rural livelihoods and agrarian change. James Currey, Melton, UK.

Hall, R., M. Edelman, S. M. Borras Jr, I. Scoones, B. White, and W. Wolford. 2015b. Resistance, acquiescence or incorporation? An introduction to land grabbing and political reactions 'from below'. The Journal of Peasant Studies 42(3-4):467-488. https:// doi.org/10.1080/03066150.2015.1036746

Hall, R., I. Scoones, and D. Tsikata. 2017. Plantations, outgrowers and commercial farming in Africa: agricultural commercialisation and implications for agrarian change. The Journal of Peasant Studies 44(3):515-537. https://doi.org/10.1080/03066150.2016.1263187

Haller, T., G. Acciaioli, and S. Rist. 2016. Constitutionality: Conditions for crafting local ownership of institution-building processes. Society and Natural Resource 29(1):68-87. https://doi. org/10.1080/08941920.2015.1041661

Haller, T., T. Adams, D. Gmür, F. Käser, K. Lanz, F. Marfurt, S. Ryser, E. Schubiger, A. von Sury, and J. D. Gerber. 2019. Largescale land acquisition as commons grabbing: a comparative analysis of six African case studies. Pages 125-164 in L. Lozny and T. McGovern, editors. Global perspectives on long term community resource management. Springer, Cham, Switzerland. https://doi.org/10.1007/978-3-030-15800-2 7

Haller, T., Käser, F., and M. Ngutu. 2020. Does commons grabbing lead to resilience grabbing? The anti-politics machine of neo-liberal agrarian development and local responses. Land 2020 (9):220. https://doi.org/10.3390/land9070220

High Level Panel of Experts on Food Security and Nutrition (HLPE). 2018. Multi-stakeholder partnerships to finance and improve food security and nutrition in the framework of the 2030 Agenda. A report by the HLPE, Committee on World Food Security, Rome, Italy.

Hosonuma, N., M. Herold, V. De Sy, R. S. De Fries, M. Brockhaus, L. Verchot, A. Angelsen, and E. Romijn. 2012. An assessment of deforestation and forest degradation drivers in developing countries. Environmental Research Letters 7 (4):044009. https://doi.org/10.1088/1748-9326/7/4/044009

Hufe, P., and D. F. Heuermann. 2017. The local impacts of largescale land acquisitions: a review of case study evidence from SubSaharan Africa. Journal of Contemporary African Studies 35 (2):168-189. https://doi.org/10.1080/02589001.2017.1307505

Ikegami, K. 2015. Corridor development and foreign investment in agriculture: implications of the ProSAVANA programme in northern Mozambique. In Land grabbing, conflict and agrarian 
environmental transformations: perspectives from East and Southeast Asia. International Academic Conference, 5-6 June 2015, Chiang Mai University, Chiang Mai, Thailand.

Ingalls, M. L., P. Meyfroidt, P. X. To, M. Kenney-Lazar, and M. Epprecht. 2018. The transboundary displacement of deforestation under REDD+: problematic intersections between the trade of forest-risk commodities and land grabbing in the Mekong region. Global Environmental Change 50:255-267. https://doi.org/10.1016/j.gloenvcha.2018.04.003

Intergovernmental Panel on Climate Change (IPCC). 2006. Guidelines for national greenhouse gas inventories. H. S. Eggleston, L. Buendia, K. Miwa, T. Ngara, and K. Tanabe, editors. National Greenhouse Gas Inventories Programme, Hayama, Japan.

Jacobi, J., S. Mukhovi, A. Llanque, H. Augstburger, F. Käser, C. Pozo, M. Ngutu, J. M. F. Delgado, B. Kiteme, S. Rist, and C. Ifejika Speranza. 2018. Operationalizing food system resilience: an indicator-based assessment in agroindustrial, smallholder farming, and agroecological contexts in Bolivia and Kenya. Land Use Policy 79:433-446. https://doi.org/10.1016/j.landusepol.2018.08.044

Ketels, C. H. and O. Memedovic. 2008. From clusters to clusterbased economic development. International Journal of Technological Learning, Innovation and Development 1 (3):375-392. https://doi.org/10.1504/IJTLID.2008.019979

Lade, S. J., B. H. Walker, and L. J. Haider. 2020. Resilience as pathway diversity: linking systems, individual, and temporal perspectives on resilience. Ecology and Society 25(3): 19. https:// doi.org/10.5751/ES-11760-250319

Lahiff, E., N. Davis, and T. Manenzhe. 2012. Joint ventures in agriculture: lessons from land reform projects in South Africa. University of the Western Cape, Cape Town, South Africa.

Lanari, N., H. Liniger, and B. Kiteme. 2016. Commercial horticulture in Kenya: adapting to water scarcity. Centre for Development and Environment (CDE) Policy Brief, CDE, Bern, Switzerland.

Lanz, K., J. D. Gerber, and T. Haller. 2018. Land grabbing, the state and chiefs: the politics of extending commercial agriculture in Ghana. Development and Change 49(6):1526-1552. https:// doi.org/10.1111/dech.12429

Lavers, T., and F. Boamah. 2016. The impact of agricultural investments on state capacity: a comparative analysis of Ethiopia and Ghana. Geoforum 72:94-103. https://doi.org/10.1016/j. geoforum.2016.02.004

Lavigne Delville, P. 2017. Pour une socio-anthropologie de l'action publique. Dans les pays 'sous régime d'aide'. Anthropologie et Développement 45:33-64. https://doi. org/10.4000/anthropodev.542

Li, T. M. 2011. Centering labor in the land grab debate. The Journal of Peasant Studies 38(2):281-298. https://doi. org/10.1080/03066150.2011.559009

Li, T. M. 2014. What is land? Assembling a resource for global investment. Transactions of the Institute of British Geographers 39(4):589-602. https://doi.org/10.1111/tran.12065
Lundsgaard-Hansen, L., F. Schneider, J. G. Zaehringer, C. Oberlack, W. Myint, and P. Messerli. 2018. Whose agency counts in land use decision-making in Myanmar? A comparative analysis of three cases in Tanintharyi Region. Sustainability 10(10):3823. https://doi.org/10.3390/su10103823

Maertens, M., and J. F. Swinnen. 2009. Trade, standards, and poverty: evidence from Senegal. World Development 37 (1):161-178 .

Magliocca, N. R., E. C. Ellis, G. R. Allington, A. de Bremond, J. Dell'Angelo, O. Mertz, P. Messerli, P. Meyfroidt, R. Seppelt, and P. H. Verburg. 2018. Closing global knowledge gaps: producing generalized knowledge from case studies of social-ecological systems. Global Environmental Change 50:1-14. https://doi. org/10.1016/j.gloenvcha.2018.03.003

Magliocca, N. R., Q. Khuc, E. Ellicott, and A. de Bremond. 2019. Archetypical pathways of direct and indirect land-use change caused by Cambodia's economic land concessions. Ecology and Society 24(2): 25. https://doi.org/10.5751/ES-10954-240225

Marfurt, F., F. Käser, and S. Lustenberger. 2016. Local perceptions and vertical perspectives of a large scale land acquisition project in Northern Sierra Leone. Homo Oeconomicus 33(3):261-279. https://doi.org/10.1007/s41412-016-0020-5

Margulis, M. E. 2012. Global food security governance: the Committee on World Food Security, Comprehensive Framework for Action and the G8/G20. Pages 231-254 in R. R. N. Weisfelt, editor. The challenge of food security: international policy and regulatory frameworks. Edward Elgar Publishing, Cheltenham, UK; Northampton, Massachusetts, USA. https://doi. org/10.4337/9780857939388.00025

Margulis, M. E., N. McKeon, S. M. Borras, Jr. 2013. Land grabbing and global governance: critical perspectives. Globalizations 10(1):1-23. https://doi.org/10.1080/14747731.2013.764151

Mawoko, Z. D., S. L. Hendriks, and A. Reys. 2018. Analysis method and interim results on food security for Mozambique. Paper presented at the 56th conference of the Agricultural Economics Association of South Africa. 25-27 September 2018, Lord Charles Hotel, Somerset West, Cape Town, South Africa.

McCord, P., J. Dell'Angelo, E. Baldwin, and T. Evans. 2017. Polycentric transformation in Kenyan water governance: a dynamic analysis of institutional and social-ecological change. Policy Studies Journal 45(4):633-658. https://doi.org/10.1111/ psj. 12168

McKeon, N. 2014. The new alliance for food security and nutrition: a coup for corporate capital? Transnational Institute (TNI) Agrarian Justice Programme Policy Paper 19. Transnational Institute, Amsterdam, The Netherlands.

Mekonnen, M. M., A. Y. Hoekstra, and R. Becht. 2012. Mitigating the water footprint of export cut flowers from the Lake Naivasha Basin, Kenya. Water Resources Management 26:3725-3742. https://doi.org/10.1007/s11269-012-0099-9

Messerli, P., M. Giger, M. D. Dwyer, T. Breu, and S. Eckert. 2014. The geography of large-scale land acquisitions: analysing socioecological patterns of target contexts in the global South. Applied Geography 53:449-459. https://doi.org/10.1016/j.apgeog.2014.07.005 
Meyfroidt, P. 2016. Approaches and terminology for causal analysis in land systems science. Journal of Land Use Science 11 (5):501-522. https://doi.org/10.1080/1747423X.2015.1117530

Meyfroidt, P., R. R. Chowdhury, A. de Bremond, E. C. Ellis, K. H. Erb, T. Filatova, R. D. Garrett, J. M. Grove, A. Heinimann, T. Kuemmerle, C. A. Kull, E. F. Lambin, Y. Landon, Y. le Polain de Waroux, P. Messerli, D. Müller, J. Ø. Nielsen, G. D. Peterson, V. Rodriguez García, M. Schlüter, B. L Turner, and P.H. Verburg. 2018. Middle-range theories of land system change. Global Environmental Change 53:52-67. https://doi.org/10.1016/j. gloenvcha.2018.08.006

Millar, G. 2016. Local experiences of liberal peace: marketization and emergent conflict dynamics in Sierra Leone. Journal of Peace Research 53(4):569-581. https://doi.org/10.1177/0022343316632580

Muriithi, F. K., and D. Yu. 2015. Understanding the impact of intensive horticulture land use practices on surface water quality in central Kenya. Environments 2:52-545. https://doi. org/10.3390/environments2040521

Nanhthavong, V., C. Oberlack, C. Hett, P. Messerli, and M. Epprecht. 2021. Pathways to human well-being in the context of land acquisitions in Lao PDR. Global Environmental Change 68: 102252. https://doi.org/10.1016/j.gloenvcha.2021.102252

Ngutu, M., S. Bukachi, C. Olungah, B. Kiteme, F. Kaeser, and T. Haller. 2018. The actors, rules and regulations linked to export horticulture production and access to land and water as common pool resources in Laikipia County, northwest Mount Kenya. Land 7(3):110. https://doi.org/10.3390/land7030110

Nolte, K. 2020. Doomed to fail? Why some land-based investment projects fail. Applied Geography 122: 102268. https://doi. org/10.1016/j.apgeog.2020.102268

Nolte, K., W. Chamberlain, and M. Giger. 2016. International land deals for agriculture: fresh insights from the land matrix: analytical report II. Centre for Development and Environment (CDE), Bern, Switzerland / Centre de coopération internationale en recherche agronomique pour le développement (CIRAD), Montpellier, France / German Institute for Global and Area Studies (GIGA), Hamburg, Germany.

Nolte, K., and M. Ostermeier. 2017. Labour market effects of large-scale agricultural investment: conceptual considerations and estimated employment effects. World Development 98:430-446. https://doi.org/10.1016/j.worlddev.2017.05.012

Nolte, K., and S. J. Väth. 2015. Interplay of land governance and large-scale agricultural investment: evidence from Ghana and Kenya. Journal of Modern African Studies 53(1):69-92. https:// doi.org/10.1017/S0022278X14000688

Oberlack, C., S. Boillat, S. Brönnimann, J. D. Gerber, A. Heinimann, C. Ifejika Speranza, P. Messerli, S. Rist, and U. M. Wiesmann. 2018. Polycentric governance in telecoupled resource systems. Ecology and Society 23(1): 16. https://doi.org/10.5751/ ES-09902-230116

Oberlack, C., D. Sietz, A. de Bremond, E. Bürgi-Bonanomi, J. Dell'Angelo, K. Eisenack, E. Ellis, G. Epstein, M. Giger, A. Heinimann, C. Kimmich, M. T. J. Kok, D. Manuel-Navarrete, P. Meyfroidt, P. Messerli, T. Václavík, and S. Villamayor-Tomás.
2019. Archetype analysis in sustainability research: meanings, motivations, and evidence-based policy-making. Ecology and Society 24(2): 26. https://doi.org/10.5751/ES-10747-240226

Oberlack, C., L. Tejada, P. Messerli, S. Rist, and M. Giger. 2016. Sustainable livelihoods in the global land rush? Archetypes of livelihood vulnerability and sustainability potentials. Global Environmental Change 41:153-171. https://doi.org/10.1016/j. gloenvcha.2016.10.001

Oliveira, G. D. L. 2016. The geopolitics of Brazilian soybeans. The Journal of Peasant Studies 43(2):348-372. https://doi. org/10.1080/03066150.2014.992337

Oya, C. 2013. Methodological reflections on 'land grab' databases and the 'land grab' literature 'rush'. The Journal of Peasant Studies 40(3):503-520. https://doi.org/10.1080/03066150.2013.799465

Palliere, A., and H. Cochet. 2018. Large private agricultural projects and job creation: from discourse to reality. Case study in Sella Limba, Sierra Leone. Land Use Policy 76:422-431. https:// doi.org/10.1016/j.landusepol.2018.02.017

Peluso, N. L., and C. Lund. 2011. New frontiers of land control: introduction. The Journal of Peasant Studies 38(4):667-681. https://doi.org/10.1080/03066150.2011.607692

Peters, P. E. 2013. Land appropriation, surplus people and a battle over visions of agrarian futures in Africa. The Journal of Peasant Studies 40(3):537-562. https://doi.org/10.1080/03066150.2013.803070

Petrick, M., J. Wandel, and K. Karsten. 2013. Rediscovering the virgin lands: agricultural investment and rural livelihoods in a Eurasian frontier area. World Development 43:164-179. https:// doi.org/10.1016/j.worlddev.2012.09.015

Porter, M. E. 2000. Location, competition, and economic development: local clusters in a global economy. Economic Development Quarterly 14(1):15-34. https://doi.org/10.1177/08$\underline{9124240001400105}$

Poteete, A. R., M. A. Janssen, and E. Ostrom. 2010. Working together: collective action, the commons, and multiple methods in practice. Princeton University Press, Princeton, New Jersey, USA; Oxford, UK. https://doi.org/10.1515/9781400835157

Purdon, M. 2013. Land acquisitions in Tanzania: strong sustainability, weak sustainability and the importance of comparative methods. Journal of Agricultural and Environmental Ethics 26(6):1127-1156. https://doi.org/10.1007/s10806-013-9442-2

Ragin, C. C. 1987. The comparative method. Moving beyond qualitative and quantitative strategies. University of California Press, Oakland, California, USA.

Rocha, J. C., M. M. Baraibar, L. Deutsch, A. de Bremond, J. S. Oestreicher, F. Rositano, and C. C. Gelabert. 2019. Toward understanding the dynamics of land change in Latin America. Ecology and Society 24(1): 17. https://doi.org/10.5751/ ES-10349-240117

Rocheleau, D. E. 2015. Networked, rooted and territorial: green grabbing and resistance in Chiapas. The Journal of Peasant Studies 42(3-4):695-723. https://doi.org/10.1080/03066150.2014.993622 
Ronald, P. C. 2014. Lab to farm: applying research on plant genetics and genomics to crop improvement. PLoS Biology 12(6): e1001878. https://doi.org/10.1371/journal.pbio.1001878

Rudel, T. K. 2008. Meta-analyses of case studies: a method for studying regional and global environmental change. Global Environmental Change 18(1):18-25. https://doi.org/10.1016/j. gloenvcha.2007.06.001

Salomão, A. 2020. Land based investments in Mozambique: challenges in community rights protection, participation and benefit sharing. Dissertation, Utrecht University, Utrecht, The Netherlands. [online] URL: https://dspace.library.uu.nl/bitstream/ handle/1874/397377/salmao.pdf

Scheidel, A., and A. H. Sorman. 2012. Energy transitions and the global land rush: ultimate drivers and persistent consequences. Global Environmental Change 22:588-595. https://doi. org/10.1016/j.gloenvcha.2011.12.005

Schneider, C. Q., and C. Wagemann. 2012. Set-theoretic methods for the social sciences: a guide to qualitative comparative analysis. Cambridge University Press, Cambridge, UK. https://doi. org/10.1017/CBO9781139004244

Schoenweger, O., and P. Messerli. 2015. Land acquisition, investment, and development in the Lao coffee sector: successes and failures. Critical Asian Studies 47(1):94-122. https://doi. org/10.1080/14672715.2015.997095

Schoneveld, G.C. 2014. The geographic and sectoral patterns of large-scale farmland investments in sub-Saharan Africa. Food Policy 48:34-50. https://doi.org/10.1016/j.foodpol.2014.03.007

Schoneveld, G. C. 2017. Host country governance and the African land rush: 7 reasons why large-scale farmland investments fail to contribute to sustainable development. Geoforum 83:119-132. https://doi.org/10.1016/j.geoforum.2016.12.007

Schoneveld, G.C., and L. German. 2014. Translating legal rights into tenure security: lessons from the new commercial pressures on land in Ghana. Journal of Development Studies 50(2):187-203. https://doi.org/10.1080/00220388.2013.858129

Schoneveld, G. C., L. German, and E. Nutakor. 2011. Land-based investments for rural development? A grounded analysis of the local impacts of biofuel feedstock plantations in Ghana. Ecology and Society 16(4): 10. https://doi.org/10.5751/ES-04424-160410

Scoones, I., R. Hall, S. M. Borras Jr, B. White, and W. Wolford. 2013. The politics of evidence: methodologies for understanding the global land rush. The Journal of Peasant Studies 40:469-483. https://doi.org/10.1080/03066150.2013.801341

Scoones, I., R. Smalley, R. Hall, and D. Tsikata. 2019. Narratives of scarcity: framing the global land rush. Geoforum 101:231-241. https://doi.org/10.1016/j.geoforum.2018.06.006

Seufert, P. 2013. The FAO voluntary guidelines on the responsible governance of tenure of land, fisheries and forests. Globalizations 10(1):181-186. https://doi.org/10.1080/14747731.2013.764157

Shete, M., and M. Rutten. 2015. Impacts of large-scale farming on local communities' food security and income levels - empirical evidence from Oromia Region, Ethiopia. Land Use Policy 47:282-292. https://doi.org/10.1016/j.landusepol.2015.01.034
Shete, M., M. Rutten, G. C. Schoneveld, and E. Zewude. 2016. Land use changes by large-scale plantations and their effects on soil organic carbon, micronutrients and bulk density: empirical evidence from Ethiopia. Agriculture and Human Values 33 (3):689-704. https://doi.org/10.1007/s10460-015-9664-1

Smalley, R. 2013. Plantations, contract farming and commercial farming areas in Africa: a comparative review. Institute for Poverty, Land and Agrarian Studies (PLAAS), Cape Town, South Africa.

Tafon, R., and F. Saunders. 2019. The politics of land grabbing: state and corporate power and the (trans)nationalization of resistance in Cameroon. Journal of Agrarian Change 19(1):41-63. https://doi.org/10.1111/joac.12264

Tejada, L., and S. Rist. 2018. Seeing land deals through the lens of the 'land-water nexus': the case of biofuel production in Piura, Peru. The Journal of Peasant Studies 45(7):1247-1271. https:// doi.org/10.1080/03066150.2016.1259220

Temper, L., D. Del Bene, and J. Martinez-Alier. 2015. Mapping the frontiers and front lines of global environmental justice: the EJAtlas. Journal of Political Ecology 22(1):255-278. https://doi. org/10.2458/v22i1.21108

Vermeulen, N., and L. Cotula. 2010. Alternatives to land acquisitions: agricultural investment and collaborative business models. International Institute for Environment and Development (IIED), London, UK; Food and Agriculture Organization (FAO), Rome Italy; International Fund for Agricultural Development (IFAD), Rome, Italy; Swiss Agency for Development and Cooperation (SDC), Bern, Switzerland.

Vijge, M. J., R. Metcalfe, L. Wallbott, and C. Oberlack. 2019. Transforming institutional quality in resource curse contexts: the extractive industries transparency initiative in Myanmar. Resources Policy 61:200-209. https://doi.org/10.1016/j. resourpol.2019.02.006

von Braun, J., and R. S. Meinzen-Dick. 2009. Land grabbing by foreign investors in developing countries: risks and opportunities. International Food Policy Research Institute, Washington, D.C., USA.

White, B., S. M. Borras, Jr., R. Hall, I. Scoones, and W. Wolford. 2012. The new enclosures: critical perspectives on corporate land deals. Journal of Peasant Studies 39(3-4):619-647. https://doi. org/10.4324/9781315871806

Wolford, W., S. M. Borras, Jr., R. Hall, I. Scoones, and B. White. 2013. Governing global land deals: the role of the state in the rush for land. Development and Change 44(2):189-210. https://doi. org/10.1002/9781118688229

Zaehringer, J. G., A. Atumane, S. Berger, and S. Eckert. 2018a. Large-scale agricultural investments trigger direct and indirect land use change: new evidence from the Nacala corridor, Mozambique. Journal of Land Use Science 13(3):325-343. https://doi.org/10.1080/1747423X.2018.1519605

Zaehringer, J. G., G. Wambugu, B. Kiteme, and S. Eckert. 2018b. How do large-scale agricultural investments affect land use and the environment on the western slopes of Mount Kenya? Empirical evidence based on small-scale farmers' perceptions and 
remote sensing. Journal of Environmental Management 213:79-89. https://doi.org/10.1016/j.jenvman.2018.02.019

Zoomers, A. 2010. Globalisation and the foreignisation of space: seven processes driving the current global land grab. The Journal of Peasant Studies 37(2):429-447. https://doi.org/10.1080/03066$\underline{151003595325}$

Zoomers, A., and K. Otsuki. 2017. Addressing the impacts of large-scale land investments: re-engaging with livelihood research. Geoforum 83:164-171. https://doi.org/10.1016/j. geoforum.2017.01.009

${ }^{1}$ The different work packages used different sampling techniques as appropriate to their methodology (e.g., household surveys, key informant interviews, remote sensing data). We constructed the present synthesis based solely on those LAIs for which sufficient data were available from multiple work packages.

${ }^{2}$ Note that contract farming does not create the equivalence of a full-time job.

${ }^{3}$ Note that due to our study design, we cannot rule out that pastoralists or prior residents - who left the area earlier-may have lost land. Furthermore, our data focus on current farms and do not indicate the extent of possible displacement decades ago when initial large-scale farms were established. 


\section{Appendix 1. Definition of indicators.}

Table A1. Definition of indicators.

\begin{tabular}{|c|c|c|c|c|}
\hline \multirow{2}{*}{ Indicators } & \multirow{2}{*}{ Description } & \multicolumn{2}{|c|}{ Measurement scale } & \multirow{2}{*}{$\begin{array}{l}\text { Data } \\
\text { sources }\end{array}$} \\
\hline & & primary data & truth table & \\
\hline \multicolumn{5}{|l|}{ Socio-economic impacts } \\
\hline Access to land lost & $\%$ of households affected (land taken by an agribusiness) & $\%$ & $0 \%, 1-33 \%, 34-66 \%, 67-100 \%$ & 1,2 \\
\hline Employment generation & $\%$ of households have at least one employee at LAI agribusiness & $\%$ & $0 \%, 1-33 \%, 34-66 \%, 67-100 \%$ & 2 \\
\hline Attitude towards LAI & $\%$ of households wishing the LAI would leave & $\%$ & $0 \%, 1-33 \%, 34-66 \%, 67-100 \%$ & 1 \\
\hline Conflict incidence & $\begin{array}{l}\text { \% of households who perceived conflict (violent or non-violent) } \\
\text { between LAI and community }\end{array}$ & $\%$ & $0 \%, 1-33 \%, 34-66 \%, 67-100 \%$ & 1 \\
\hline Infrastructure improvements & $\begin{array}{l}\text { \% of households who perceived benefits from infrastructure } \\
\text { development through LAI }\end{array}$ & $\%$ & $0 \%, 1-33 \%, 34-66 \%, 67-100 \%$ & 1 \\
\hline \multicolumn{5}{|l|}{ Environmental impacts } \\
\hline Perceived chemical exposure & $\%$ of households report chemical exposure from LAI & $\%$ & $0 \%, 1-33 \%, 34-66 \%, 67-100 \%$ & 1 \\
\hline Perceived deforestation & $\%$ of households report deforestation through LAI & $\%$ & $0 \%, 1-33 \%, 34-66 \%, 67-100 \%$ & 1 \\
\hline Perceived over-abstraction of water & $\%$ of households report water over-abstraction through LAI & $\%$ & $0 \%, 1-33 \%, 34-66 \%, 67-100 \%$ & 1 \\
\hline Perceived water pollution with chemicals and effluents & $\%$ of households report water pollution through LAI & $\%$ & $0 \%, 1-33 \%, 34-66 \%, 67-100 \%$ & 1 \\
\hline Perceived air pollution with chemicals & $\%$ of households report air pollution through LAI & $\%$ & $0 \%, 1-33 \%, 34-66 \%, 67-100 \%$ & 1 \\
\hline Perceived increase in pests & $\%$ of households report pest increase through LAI & $\%$ & $0 \%, 1-33 \%, 34-66 \%, 67-100 \%$ & 1 \\
\hline Perceived occupation of water source & $\%$ of households report occupation of water source through LAI & $\%$ & $0 \%, 1-33 \%, 34-66 \%, 67-100 \%$ & 1 \\
\hline Pesticide use & $\begin{array}{l}\text { g AI.ha-1 per annum (in life-cycle assessment), converted into scale } \\
1 . .4 \text { in expert assessment }\end{array}$ & $1 . .4$ & $1 . .4$ (see Appendix B) & 3 \\
\hline Eutrophication potential & $\begin{array}{l}\text { g PO4-e.ha-1 per annum (in life-cycle assessment), converted into } \\
\text { scale } 1 . .4 \text { in expert assessment }\end{array}$ & $1 . .4$ & 1..4 (see Appendix B) & 3 \\
\hline Acidification potential & $\begin{array}{l}\text { g SO2-e.ha-1 per annum (in life-cycle assessment), converted into } \\
\text { scale 1..4 in expert assessment }\end{array}$ & $1 . .4$ & 1..4 (see Appendix B) & 3 \\
\hline Global warming potential & $\begin{array}{l}\text { kg CO2-e.ha-1per annum (in life-cycle assessment), converted into } \\
\text { scale 1..4 in expert assessment }\end{array}$ & $1 . .4$ & 1..4 (see Appendix B) & 3 \\
\hline Non-renewable energy consumption & $\begin{array}{l}\text { MJ.ha-1 per annum (in life-cycle assessment), converted into scale } \\
1 . .4 \text { in expert assessment }\end{array}$ & $1 . .4$ & 1..4 (see Appendix B) & 3 \\
\hline Water consumption (blue and green water) & $\begin{array}{l}\text { m3.ha-1 per annum (in life-cycle assessment), converted into scale } \\
1 . .4 \text { in expert assessment }\end{array}$ & $1 . .4$ & 1..4 (see Appendix B) & 3 \\
\hline Soil degradation & $\begin{array}{l}\% \mathrm{~N} \text { and } \% \mathrm{OC} \text { change (in life-cycle assessment), converted into scale } \\
1 . .4 \text { in expert assessment }\end{array}$ & $1 . .4$ & 1..4 (see Appendix B) & 3 \\
\hline
\end{tabular}




\begin{tabular}{|c|c|c|c|c|}
\hline \multirow{2}{*}{ Indicators } & \multirow{2}{*}{ Description } & \multicolumn{2}{|c|}{ Measurement scale } & \multirow{2}{*}{$\begin{array}{c}\text { Data } \\
\text { sources }\end{array}$} \\
\hline & & primary data & truth table & \\
\hline \multicolumn{5}{|l|}{ Food security impacts } \\
\hline Food consumption score & a composite score, measuring food frequency and dietary diversity & numerical & \multirow{7}{*}{$\begin{array}{l}\text { Scale of } 1 . .4 \text { with: } \\
\text { Comparison of engaged } \\
\text { households }(\mathrm{EN}) \text {, non-engaged } \\
\text { households }(\mathrm{NE}) \text { and households } \\
\text { in counterfactual areas }(\mathrm{CF}) \text { : } \\
\text { 4: } \mathrm{EN}>\mathrm{NE} \text { and } \mathrm{EN}>\mathrm{CF} \\
\text { 3: equal }(\sim) \\
\text { 2: spreading }(\uparrow) \\
\text { 1: } \mathrm{EN}<\mathrm{NE} \text { and } \mathrm{EN}<\mathrm{CF}\end{array}$} & 2 \\
\hline Household dietary diversity score & $\begin{array}{l}\text { household dietary diversity as a proxy measure of household food } \\
\text { access }\end{array}$ & numerical & & 2 \\
\hline Women's dietary diversity score & $\begin{array}{l}\text { women's dietary diversity as a proxy measure of household food } \\
\text { access }\end{array}$ & numerical & & 2 \\
\hline Assets & $\begin{array}{l}\text { simply sum of household assets used as a proxy of household } \\
\text { resilience }\end{array}$ & numerical & & 2 \\
\hline Months of adequate household food provision & sum of the months of adequate provision & numerical & & 2 \\
\hline Coping strategies & $\begin{array}{l}\text { the frequency and severity of behaviours that household engaged in } \\
\text { to mitigate food shortages }\end{array}$ & numerical & & 2 \\
\hline Food security index & indicator of current status and coping capacity & numerical & & 2 \\
\hline \multicolumn{5}{|l|}{ On-site land use change } \\
\hline LUC on-site_agricultural expansion through LAI & yes if cropland replaces vegetation & $0 / 1$ & $0 / 1$ & 5 \\
\hline LUC on-site_agricultural intensification through LAI & yes if SSF cropland --> Irrigated cropland and/or --> greenhouses & $0 / 1$ & $0 / 1$ & 5 \\
\hline Net change small-scale farming cropland & \multirow{11}{*}{$\begin{array}{l}\text { gain minus losses of land use category within LAI area between } 2000 \\
\text { and } 2015\end{array}$} & \multirow{11}{*}{ ha, $\%$ of area } & \multirow{11}{*}{$\begin{array}{l}\text { aggregated into agricultural } \\
\text { expansion/intensification } \\
\text { indicator }\end{array}$} & 5 \\
\hline Net change surface water & & & & 5 \\
\hline Net change irrigated cropland & & & & 5 \\
\hline Net change grassland & & & & 5 \\
\hline Net change forest & & & & 5 \\
\hline Net change greenhouses & & & & 5 \\
\hline Net change bushland-shrubland & & & & 5 \\
\hline $\begin{array}{l}\text { Net change LAI cropland (soya, macadamia, tea, } \\
\text { banana, vegetables, sisal) }\end{array}$ & & & & 5 \\
\hline $\begin{array}{l}\text { Net change LAI mechanized irrigated cropland (pivot } \\
\text { irrigation) }\end{array}$ & & & & 5 \\
\hline Net change cultivated wetlands & & & & 5 \\
\hline Net change natural wetlands & & & & 5 \\
\hline
\end{tabular}




\begin{tabular}{|c|c|c|c|c|}
\hline \multirow{2}{*}{ Indicators } & \multirow{2}{*}{ Description } & \multicolumn{2}{|c|}{ Measurement scale } & \multirow{2}{*}{$\begin{array}{l}\text { Data } \\
\text { sources }\end{array}$} \\
\hline & & primary data & truth table & \\
\hline \multicolumn{5}{|l|}{ Off-site land use change } \\
\hline $\begin{array}{l}\text { LAI is "agricultural intensification enclave" in its } \\
\text { doughnut }\end{array}$ & $\begin{array}{l}\text { yes if LAI intensification occurs despite doughnut reduced } \\
\text { agricultural intensity }\end{array}$ & $0 / 1$ & $0 / 1$ & 5 \\
\hline $\begin{array}{l}\text { LAI is part of agricultural intensification/expansion } \\
\text { boom in its doughnut }\end{array}$ & yes if LAI intensification occurs parallel to doughnut intensification & $0 / 1$ & $0 / 1$ & 5 \\
\hline Net change small-scale farming cropland & \multirow{11}{*}{$\begin{array}{l}\text { gain minus losses of land use category in } 5 \mathrm{~km} \text { buffer around LAI } \\
\text { area between } 2000 \text { and } 2015\end{array}$} & \multirow{11}{*}{$\begin{array}{l}\text { ha and } \% \text { of } \\
\text { area }\end{array}$} & \multirow{11}{*}{$\begin{array}{l}\text { aggregated into indicators } \\
\text { "agricultural intensification } \\
\text { encave/boom" }\end{array}$} & 5 \\
\hline Net change surface water & & & & 5 \\
\hline Net change irrigated cropland & & & & 5 \\
\hline Net change grassland & & & & 5 \\
\hline Net change forest & & & & 5 \\
\hline Net change greenhouses & & & & 5 \\
\hline Net change bushland-shrubland & & & & 5 \\
\hline $\begin{array}{l}\text { Net change LAI cropland (soya, macadamia, tea, } \\
\text { banana, vegetables, sisal) }\end{array}$ & & & & 5 \\
\hline $\begin{array}{l}\text { Net change LAI mechanized irrigated cropland (pivot } \\
\text { irrigation) }\end{array}$ & & & & 5 \\
\hline Net change cultivated wetlands & & & & 5 \\
\hline Net change natural wetlands & & & & 5 \\
\hline \multicolumn{5}{|l|}{ Indirect land use change } \\
\hline Small-scale farming driven deforestation_none & $\%$ of households reporting small-scale farming driven deforestation & $\%$ & $0 / 1$ & 1 \\
\hline $\begin{array}{l}\text { Land management change on small-scale farming fields } \\
\text { due to LAI }\end{array}$ & $\begin{array}{l}\% \text { of households reporting land management change on small-scale } \\
\text { farming fields due to LAI }\end{array}$ & $\%$ & $0 / 1$ & 1 \\
\hline LAI mechanization & expert assessment of degree of mechanization & $\begin{array}{l}\text { low, medium, } \\
\text { high }\end{array}$ & low, medium, high & 3 \\
\hline LAI input intensity & expert assessment of degree of input intensity & $\begin{array}{l}\text { low, medium, } \\
\text { high }\end{array}$ & low, medium, high & 3 \\
\hline
\end{tabular}




\begin{tabular}{|c|c|c|c|c|}
\hline \multirow{2}{*}{ Indicators } & \multirow{2}{*}{ Description } & \multicolumn{2}{|c|}{ Measurement scale } & \multirow{2}{*}{$\begin{array}{l}\text { Data } \\
\text { sources }\end{array}$} \\
\hline & & primary data & truth table & \\
\hline \multicolumn{5}{|l|}{ Business models } \\
\hline Crop & $\begin{array}{l}\text { type of crop (cashew nuts, cereals, flowers, forestry, fruits, jatropha, } \\
\text { livestock, macadamia, maize, rice, sisal, soybean, vegetables, tea, } \\
\text { other) }\end{array}$ & type & type & 4 \\
\hline Farm size (acquired land) & size of acquired land & ha & $<100$ ha, $100-1000$ ha, $>1000$ ha & 4 \\
\hline Farm size (land in operation) & size of land in operation & ha & $<100$ ha, $100-1000$ ha, $>1000$ ha & 4 \\
\hline Utilization of land leased & $\begin{array}{l}\text { share of farm size (land in operation) in relation to farm size } \\
\text { (acquired land) }\end{array}$ & $\%$ & $0-33 \%, 34-66 \%, 67-100 \%$ & 4 \\
\hline Number of jobs & number of jobs & numerical & $<100,100-1000,>1000$ & 4 \\
\hline Share permanent & share (semi-)permanent jobs ( $>8$ months) of total jobs & $\%$ & $0-33 \%, 34-66 \%, 67-100 \%$ & 4 \\
\hline Labour intensity & total jobs per ha & numerical & $<1,1-10,>10$ & 4 \\
\hline Prior land use & $\begin{array}{l}\text { type of prior land use: small-scale farming; pastoralist; large-scale } \\
\text { farm (defunct); large-scale farm (operational); communal forestry; } \\
\text { nature reserve; other (if mixed, use dominant) }\end{array}$ & type & type & 4 \\
\hline Age of investment & age of investment (at time of fieldwork in 2017) & numerical & $<2,2-5,6-10,>10$ years & 4 \\
\hline In-country experience in agriculture & $\begin{array}{l}\text { type: investor with long-term experience in "local" agriculture; } \\
\text { newcomer to agriculture; newcomer to country }\end{array}$ & type & type & 4 \\
\hline Nationality of investors & $\begin{array}{l}\text { domestic; international; settlers' descendants; prior colonial country; } \\
\text { joint venture }\end{array}$ & type & type & 4 \\
\hline Nationality of managers & domestic; international; settlers' descendants; prior colonial country & type & type & 4 \\
\hline Juridical structure & $\begin{array}{l}\text { Individual entrepreneur (1); private with shareholding (2); private } \\
\text { without shareholding (3); investment fund (4); public (5) }\end{array}$ & type & type & 4 \\
\hline Degree of corporate dependence & Independent (1); affiliates of large company (2) & type & type & 4 \\
\hline Degree of vertical integration & $\begin{array}{l}\text { scale: } 1-4 \text { with: } 1 \text { (only independent production); } 4 \text { (high vertical } \\
\text { integration, incl. production; in-house production of inputs; } \\
\text { packaging; marketing etc.). }\end{array}$ & type & type & 4 \\
\hline Organization of production model & own production + own management; outgrowers; contract farming & type & type & 4 \\
\hline Main market & local (1); national (2); international (3) & type & type & 4 \\
\hline Irrigation technique & drip (1); overhead (2); none (3) & type & type & 4 \\
\hline Investor land access & purchase; inheritance; lease with state; lease with private; rent & type & type & 4 \\
\hline Status of operations & full operation; struggling; (failed) & type & type & 4 \\
\hline CSR activities & existence $(1)$ or not $(0)$ & type & type & 4 \\
\hline Sustainability standards & none/GlobalGAP/GlobalGAP and others & type & type & 4 \\
\hline
\end{tabular}




\begin{tabular}{|c|c|c|c|c|}
\hline \multirow{2}{*}{ Indicators } & \multirow{2}{*}{ Description } & \multicolumn{2}{|c|}{ Measurement scale } & \multirow{2}{*}{$\begin{array}{l}\text { Data } \\
\text { sources }\end{array}$} \\
\hline & & primary data & truth table & \\
\hline \multicolumn{5}{|l|}{ Governance system } \\
\hline Experience of policymakers with LAIs & past experience of policymakers with LSAIs: strong (1) or weak (0) & binary & binary & 6 \\
\hline Agricultural and food security policy discourse & $\begin{array}{l}\text { favourable for LAI development: }-2 \text { : not at all favourable policy } \\
\text { framework (agricultural and food security policy); } 0: \text { neutral; }+2 \text { : } \\
\text { strongly favourable for LAI }\end{array}$ & $-2 . .0 . .+2$ & 5-point scale & 6 \\
\hline Country-specific pro-LAI policy reforms (recent) & $\begin{array}{l}\text { general policy reform favours LAI; land policy reform favours LAI; } \\
\text { no LAI-favouring policy reforms: existence (1) or no existence (0) }\end{array}$ & binary & binary & 6 \\
\hline Level of extraversion & $\begin{array}{l}\text { weight of international aid in national budget: low (0), medium (1), } \\
\text { high (2) level of extraversion of policies }\end{array}$ & $0 . .2$ & 3-point scale & 6 \\
\hline Degree of "development brokering" & $\begin{array}{l}\text { numbers of intermediaries to be "contacted" by investors: a lot (2)/ } \\
\text { few (1)/ none }(0)\end{array}$ & $0 . .2$ & 3-point scale & 6 \\
\hline Level of fragmentation of policymaking process & $\begin{array}{l}\text { coordinated or not (existence of effective coordination institutions } \\
\text { etc) }\end{array}$ & binary & binary & 6 \\
\hline Level of fragmentation of policymaking process & low or significant impact of fragmentation on LAIs devlpt & binary & binary & 6 \\
\hline Civil society mobilization capacity & $\begin{array}{l}\text { high (1) or low (0): number of CS organizations, convergence of } \\
\text { positions (the more convergence, the more the capacity to influence } \\
\text { policymaking process), political resources available }\end{array}$ & binary & binary & 6 \\
\hline $\begin{array}{l}\text { Degree of financial independence/autonomy of NGOs } \\
\text { (level of extraversion) }\end{array}$ & $\begin{array}{l}\text { high (1) or low (0): funding model based on donors' subsidies } \\
\text { favours more standardized position (position de principe) }\end{array}$ & binary & binary & 6 \\
\hline $\begin{array}{l}\text { Legal compensation systems with moderate } \\
\text { compensation levels present but mixed implementation }\end{array}$ & & binary & binary & 6 \\
\hline Legal compensation systems for using community land & existence $(1)$ or not $(0)$ & binary & binary & 6 \\
\hline Legal compensation systems for using community land & concrete implementation (1) or not (0) & binary & binary & 6 \\
\hline Type of compensation of people losing access to land & none; legal minimum; company's compensation & binary & binary & 6 \\
\hline Actual compensation & money / land / infrastructures / services / none & type & type & 6 \\
\hline $\begin{array}{l}\text { Land property rights: legal status of land on the } \\
\text { company's plots }\end{array}$ & type & type & type & 6 \\
\hline $\begin{array}{l}\text { Land property rights: local/customary status of land (on } \\
\text { the company's plots before company arrival) }\end{array}$ & type & type & type & 6 \\
\hline Actual land tenure security for large-scale farms & high, low & binary & binary & 6 \\
\hline $\begin{array}{l}\text { Actual land tenure security (smallholders/families) on } \\
\text { the company's plots before company arrival }\end{array}$ & high, low & binary & binary & 6 \\
\hline $\begin{array}{l}\text { Actual land tenure security (smallholders/families) on } \\
\text { neighbouring plots }\end{array}$ & high, low & binary & binary & 6 \\
\hline
\end{tabular}




\begin{tabular}{|c|c|c|c|c|}
\hline \multirow{2}{*}{ Indicators } & \multirow{2}{*}{ Description } & \multicolumn{2}{|c|}{ Measurement scale } & \multirow{2}{*}{$\begin{array}{l}\text { Data } \\
\text { sources }\end{array}$} \\
\hline & & primary data & truth table & \\
\hline \multicolumn{5}{|l|}{ Governance system (continued) } \\
\hline Consultation in land deal & strong voice - no voice or absent consultation (or if available: type) & binary & binary & 6 \\
\hline Accountability of community leaders to land users & strong - weak & binary & binary & 6 \\
\hline Accountability of government to land users & strong - weak & binary & binary & 6 \\
\hline State authority in land governance & centralized / fragmented & binary & binary & 6 \\
\hline Access of smallholders to state authority & rating on scale $1-4$ with 1 : very weak; 4 : very strong & $1 . .4$ & $1 . .4$ & 6 \\
\hline \multicolumn{5}{|l|}{ Social-ecological context } \\
\hline Yield potential & high - medium - low & $1 . .3$ & $1 . .3$ & 3 \\
\hline Actual yields & high - medium - low & $1 . .3$ & $1 . .3$ & 3 \\
\hline No. of growing days in the region & days & ordinal & $180-209 ; 240-269 ; 300-329$ & 3 \\
\hline Employment elsewhere & $\begin{array}{l}\% \text { of households having at least one member in wage labour in other } \\
\text { firm than LAI }\end{array}$ & $\%$ & $0 \%, 1-33 \%, 34-66 \%, 67-100 \%$ & 1 \\
\hline Water source for irrigation & predom. below ground, predom. above ground & binary & binary & 1 \\
\hline Fertilizer use by small-scale farmers & $\%$ of small-scale farmer households using fertilizer & $\%$ & $0-33 \%, 34-66 \%, 67-100 \%$ & 1 \\
\hline
\end{tabular}

Notation: Data sources: (1) Household interviews of work package 3. (2) Household survey of work package 4 (n=504-601 per country). (3) Household interviews, life-cycle assessment, and expert assessment. (4) Semi-structured interviews with company managers ( $\mathrm{n}=68$ ). (5) Remote-sensing analyses. (6) Key-informant interviews and document analysis for data on governance systems. (references see in the methodology section of the main text). 


\section{Appendix 2. Additional information on the data collection and analysis}

\section{Food security indicator methodology}

Food security is multidimensional and has no single internationally recognized measure (Hendriks et al. 2016). Therefore, we used seven internationally recognized food security indicators to evaluate and compare the groups in the two study areas. The methodology to calculate these is detailed below.

The Household Dietary Diversity Score (HDDS) is a recognized measure of diet quality (Hendriks et al. 2016; Hirvonen, Taffesse, \& Hassen, 2016; IFPRI 2006). The HDDS captured the number of food groups consumed within the previous 24 hours (FANTA 2006). The score is the sum of binary responses regarding the consumption of 12 food groups. We grouped households into by lowest dietary diversity (HDDS $\leq 3$ ), medium dietary diversity (HDDS 4 and 5), and high dietary diversity (HDDS $\geq 6$ ) (FAO 2006).

The Food Consumption Score (FCS) is derived from a seven-day recall similar to the HDDS (WFP 2008). The FCS is a composite score of the frequency of consumption over the previous seven days and then weighted by a coefficient (Hendriks et al. 2016; Leroy 2015; WFP 2008). The score is obtained as follows:

FCS $=($ days of staple consumption) $* 2+$ (number of days pulses consumed) $* 3+$ (number of days vegetables and leaves consumed) + (number of days fruit consumed) + (number of days meat/fish/eggs consumed) $* 4+$ (number of days dairy consumed) $* 4+$ (number of days sugar/honey consumed) $* 0.5+$ (number of days of oils and fats consumed) $* 0.5$.

The results were classified as: 0-21 for poor food consumption, 21.5-35 for borderline food consumption, and above 35 for acceptable food consumption (WFP 2008).

The Women's Dietary Diversity Score (WDDS) assessed the micronutrient adequacy of the diets of women of reproductive age (15-49 years of age) (FAO and FHI, 2016). For this indicator, we could only use the data for female-headed households and assume that the responses to the questions on consumption by the household head reflected women's dietary patterns. The score was also derived from the 24-hour recall food consumption data, but we reclassified the responses according to nine food groups based on nutritional importance (Chagomoka et al. 2016; FAO 2011; Kennedy 2010; Leroy 2015). The WDDS was classified into three categories according to (Chagomoka et al. 2017).

The Months of Adequate Household Food Provisioning (MAHFP), measures household food access over a year (Africare 2007; Bilinsky and Swindale 2010). The score was the sum of the months of adequate provision (Bilinsky and Swindale 2010). The households were classified into three categories as indicated by Africare (2007).

The Coping Strategies Index (CSI) indirectly measures food security by asking questions related to food consumption behaviour (Hendriks et al. 2016; Leroy 2015; Maxwell and Caldwell 2008). The CSI was calculated by multiplying the frequency and severity of behaviours that households engaged in to mitigate food shortages from a seven-day recall period following Maxwell and Caldwell's (2008) methodology:

$C S I=($ frequency $C S 1 *$ severity $C S 1)+($ frequency $C S 2 *$ severity $C S 2)+\ldots+($ frequency $C S 10 *$ severity $C S 10)$ 
An asset ownership indicator was used as a proxy for household resilience (ability to cope with shocks) (Swift 2006). Low asset levels increase vulnerability to poverty and hunger (food insecurity) (Chambers 2006; Maxwell and Smith 1992). We used a simple sum of household assets classes. The sum does not reflect the value of assets (Browne et al. 2014; Hendriks et al. 2016).

A modified Consolidated Approach for Reporting Indicators of Food Security (CARI) console was also used for comparative analysis (WFP 2012). The CARI combines food security indicators (current status and coping capacity) into a summary called the Food Security Index (FSI), representing the overall food security status (Butaumocho and Chitiyo 2017). The CARI used a combination of three food security indicators (i.e. food consumption score, food expenditure shares, and livelihood coping strategy). Due to a lack of livelihood coping strategy-related indicators in the database, we converted the data regarding the application of the more serious consumption-based coping strategies (i.e. adult hunger, child hunger, and eating fewer meals) into a livelihood coping strategy score. Households were classified into four groups: food secure, marginally food secure, moderately food insecure, and severely food insecure) (WFP 2014).

A chi-square test was used to check the significant difference between the household groups in the two case studies and the four household groups. Spearman's correlation was used to examine the nonparametric relation between food security indicators (HDDS, FCS, MAHFP, CSI, and Asset).

\section{Socio-economic and food security impacts}

On socio-economic impacts and food-security impacts in Kenya, only aggregated data for the cases KE1-5 were available; we used this data as "best available data" for these LAI cases. Food security scores for Kenya were calculated without case KE6, because we were not able to include the KE6 case into formal analysis due to missing data on the indicators from other work packages.

\section{Environmental impact scoring (indicators ENV1-7 and ENV 11-17)}

We used 14 indicators to assess environmental impacts combining participatory and expert-based assessments of environmental impacts. Half of them (indicators ENV1-7) are based on semi-structured interviews that measure households' perceptions of chemical exposure, deforestation, overabstraction of water, water pollution with chemicals and effluents, air pollution with chemicals/respiratory problems, increase in pests and occupation of water sources. For each indicator, we quantified the share of households perceiving this environmental impact. We classified this data into very low impacts $(0 \%$ of households perceive this environmental impact); low (1-33\%); medium (34-66\%); and high impacts $(67-100 \%)$.

The other half of our data on environmental impacts (indicators ENV11-17) are based on interviews with LAI and small-scale farmers, corresponding with lifecycle assessments and expert assessments. Environmental impact scoring for the different cropping systems was based on a per surface area (one hectare) basis. Life cycle assessment (LCA) metrics for global warming potential, eutrophication potential, acidification potential, non-renewable energy consumption, and water consumption were calculated for specific case studies (Da Silva, 2018) and used to inform the scoring. Extent of pesticide consumption and soil degradation in the form of decline of soil organic matter and nutrient mining were also considered (Ottinger, 2018; Da Silva, 2018). Table A2 was further used to guide the selection of an impact score based on intensity of resource use. It is also acknowledged that some degree of subjectivity was needed to assign impacts scores to different case studies due to lack of data. 
For water consumption, systems solely dependent on rainfall were scored as having "very low" or "low" impact. For Kenya, flower production in greenhouses was difficult to score. While most of these systems may operate under open fertigation thus scoring "high" impact, one must also consider that production is occurring in a more controlled environment with lower atmospheric water demand and there may be rainwater harvesting from the roof of the greenhouses for irrigation purposes. It is also possible that any over-irrigation may be returned to the system and available to other users downstream (non-consumptive, recoverable fraction). Soil degradation is an equally challenging category to score for greenhouse production. While the soil under the greenhouses is protected from erosion and crusting due to the overhead cover and micro-irrigation potentially leading to reduced impact, a large amount of agrochemicals are applied to these soils, and it was also indicated that these soil needs to be replaced every nine or ten years.

Pesticide use on its own does not represent direct impact, but it has been reported that less than $0.1 \%$ reaches the intended pest (Pimentel and Levitan 1986), so the extent of use is applied here to score the potential impact. Acidification potential is linked to the amount of energy used in the form of agrochemical synthesis, transport and application, as well as more direct on-farm energy consumption (electricity, diesel).

An alternative to assessing the impact on a surface-area basis could have been per unit production. In many cases while the impact of an LAI is relatively higher per surface area than for a small-scale farmer, when considered per unit production the relative impact of the LAI would be lower or even more favourable compared to SSF production.

Table B1. Criteria used in addition to life-cycle assessment metrics used to score environmental impact for different case studies

\begin{tabular}{|c|c|c|c|c|}
\hline Impact category & 1 -Very low impact & 2 - Low impact & 3 - Moderate impact & 4 - High impact \\
\hline Pesticide use & No use of pesticides & Low use of pesticides & Moderate use of pesticides & High use of pesticides \\
\hline Eutrophication potential & No use of fertilisers & Low use of fertilisers & Moderate use of fertilisers & High use of fertilisers \\
\hline Acidification potential & $\begin{array}{l}\text { No use of agro-chemicals and/or } \\
\text { mechanisation }\end{array}$ & $\begin{array}{l}\text { Low use of agro-chemicals and/or } \\
\text { mechanisation }\end{array}$ & $\begin{array}{l}\text { Moderate use of agro-chemicals and/or } \\
\text { mechanisation }\end{array}$ & $\begin{array}{l}\text { High use of agro-chemicals and/or } \\
\text { mechanisation }\end{array}$ \\
\hline Global warming potential & $\begin{array}{l}\text { No use of agro-chemicals and/or } \\
\text { mechanisation }\end{array}$ & $\begin{array}{l}\text { Low use of agro-chemicals and/or } \\
\text { mechanisation }\end{array}$ & $\begin{array}{l}\text { Moderate use of agro-chemicals and/or } \\
\text { mechanisation }\end{array}$ & $\begin{array}{l}\text { High use of agro-chemicals and/or } \\
\text { mechanisation }\end{array}$ \\
\hline Non-renewable energy conumption & High resource use efficiency & Moderate resource use efficiency & Low resource use efficiency & Very low resource use efficiency \\
\hline Water consumption (blue and green water) & Very low water consumption & Low water consumption & Moderate water consumption & High water consumption \\
\hline Soil degradation & High use of soil conservation measures & Moderate use of soil conservation measures & Low use of soil conservation measures & No use of soil conservation measure: \\
\hline
\end{tabular}

The standards for LCA methodology were set by the International Organization for Standardization (ISO) and were defined in ISO 14040 (ISO 2006). This methodology was applied in this study to assess a range of Environmental Impacts (EIs), using LCA methodology to quantify potential off-site environmental impact indicators, namely: Eutrophication Potential (EP), Acidification Potential (AP), Global Warming Potential (GWP), the Water Footprint (WF), and Non-Renewable Energy (NRE) consumption. Further, the APSIM model calibrated with local soil and weather data was used to quantify on-site soil degradation (soil organic carbon (C) and total soil nitrogen (N) depletion) and investigate yield gaps for each system.

\section{Land use changes}

For the truth table, we transformed percentage values of indicators into four classes $(0 \%, 1-33 \%, 34$ $66 \%, 67-100 \%$ ). We treated the land cover and land use change (LCLUC) data in the following ways: (1) Distinguish on-site ("LAI") and off-site LCLUC ("Doughnut"). (2) Calculate net change per LCLU class (ha). (3) Identify and flag the two most increasing and the two most decreasing LCLU classes per LAI case and per region. Comparison with relative LCLUC (\%) and with stable LCLU classes (ha) to check whether changes are large or small. (4) Assign "1" to the two most growing and most diminishing LUCs per LAI case: on-site and off-site. 
Off-site LCLUC in the cases MO1-3 cannot be assigned to a specific LAI because these LAIs are very close to each other. Therefore, we assigned the same LCLUC values to each of the three LAI cases MO1-3.

\section{National governance systems}

We used the data on national governance systems and regional social-ecological contexts for each LAI within that context. 


\section{Literature cited}

Africare. 2007. Guidance: How to measure Months of Adequate Household Food Provisioning (MAHFP) based on participatory rural appraisals in food security interventions. Africare Food Security Review, No. 1. Africare, Washington DC, USA.

Bilinsky, P., and A. Swindale. 2010. Months of adequate household food provisioning (MAHFP) for measurement of household food access: Indicator guide. Version 4. Washington DC, USA: Food and Nutrition Technical Assistance II Project (FANTA).

Browne, M., G. F. Ortmann, and S. L. Hendriks. 2014. Developing a resilience indicator for food security monitoring and evaluation. Agrekon 53(2):25:46.

Butaumocho, B., and P. T. Chitiyo. 2017. A comparative analysis of household food security measure in rural Zimbabwe. International Journal of Food and Agricultural Economics $5(2): 41-58$.

Chagomoka, T., A. Drescher, R. Glaser, B. Marschner, J Schlesinger, and G. Nyandoro. 2017. Contribution of urban and periurban agriculture to household food and nutrition security along the urban-rural continuum in Ouagadougou, Burkina Faso. Renewable Agriculture and Food Systems 32(1):5-20.

FANTA (Food and Nutrition Technical Assistance Project). 2006. Household Dietary Diversity Score (HDDS) for measurement of household food access: Indicator guide (Version 2). FANTA, Washington DC, USA.

FAO (Food and Agricultural Organization of the United Nations). 2006. Food Security. Policy Brief No. 2. June. FAO, Rome, Italy.

FAO, FHI 360. 2016. Minimum dietary diversity for women: A guide for measurement. FAO, Rome, Italy. 2016.

Hendriks, S. L., C. van der Merwe, M. S. Ngidi, C. Manyamba, M. Mbele, A. M. McIntyre, E. Mkandawire, Q. N. Molefe, M. Q. Mphephu, and L. Ngwane. 2016. What are we measuring? Comparison of household food security indicators in the Eastern Cape Province, South Africa. Ecology of food and nutrition 55(2):141-162.

Hirvonen, K., A. S. Taffesse, I. W. Hassen. 2016. Seasonality and household diets in Ethiopia. Public Health Nutrition 19(10):1723-1730.

IFPRI (International Food Policy Research Institute). 2006. Review and validation of dietary diversity, food frequency and other proxy indicators of household food security. Report submitted to the World Food Programme, Rome, Italy.

ISO (International Organization for Standardization). 2006. Environmental management Life cycle assessment - Principles and framework. ISO 14040:2006. ISO, Geneva, Switzerland.

Kennedy, G., M. Razes, T. Ballard, and M. C. Dop. 2010. Measurement of dietary diversity for monitoring the impact of food based approaches. In: International symposium on food and nutrition security: food-based approaches for improving diets and raising levels of nutrition. FAO, Rome, Italy. 
Leroy, J. L., M. Ruel, E. A. Frongillo, J. Harris, and T. J. Ballard. 2015. Measuring the food access dimension of food security: a critical review and mapping of indicators. Food and Nutrition Bulletin 36(2):167-195.

Maxwell, D., and R. Caldwell. 2008. The Coping Strategies Index: Field methods manual. 2nd edition. Cooperative for Assistance and Relief Everywhere (CARE), USA.

Maxwell, S., and M. Smith. 1992. Household food security: a conceptual review. In: Maxwell, S., and T. Frankenberger (eds.) Household food security: concepts, indicators, measurements. International Fund for Agricultural Development (IFAD) and United Nations International Children's Emergency Fund (UNICEF). Rome and New York, pp. 1-72.

Swift, J. 2006. Why are rural people vulnerable to famine? IDS Bulletin 37(4):41-49.

WFP (World Food Programme). 2012. Guidance note: Calculation of household food security outcome indicators (WFP Vulnerability Analysis and Mapping Unit, Afghanistan December 2012).

Available from:

https://www.humanitarianresponse.info/ru/system/files/documents/files/guidance_note__calculation_of_fcs_rcsi_hhs_and_dd.docx; Accessed May 02, 2020.

WFP (World Food Programme). 2008. Vulnerability analysis and mapping. Food consumption analysis: Calculation and use of the food consumption score in food security analysis. WFP, Rome, Italy. 
Appendix 3. Overview of attributes characterizing the main analytical concepts

Please click here to download file 'appendix3.xlsx'. 